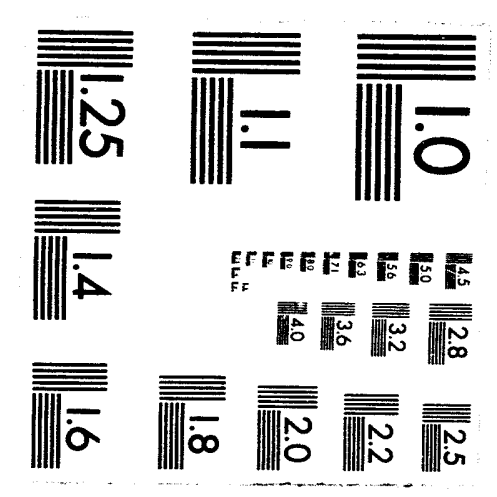





\title{
Study of High Energy Ion Loss During Hydrogen Minority Heating in TFTR
}

\author{
Jaeyoung Park, Stewart J. Zweben \\ Princeton Plasma Physics Laboratory, P.O.Box 451 \\ Princeton, NJ 08543
}

\begin{abstract}
High energy ion loss during hydrogen minority ICRF heating is measured and compared with the loss of the D-D fusion products. During $\mathrm{H}$ minority heating a relatively large loss of high energy ions is observed at $45^{\circ}$ below the outer midplane, with or without simultaneous NBI heating. This increase is most likely due to a loss of the minority tail protons, a possible model for this process is described.
\end{abstract}

\section{MASTER}

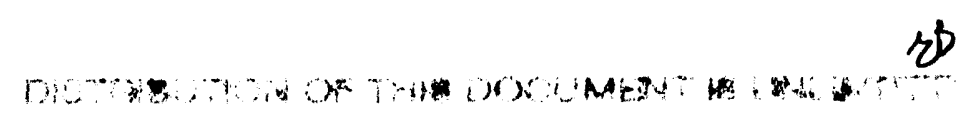




\section{Introduction}

Since alpha particle confinement is a very important issue for the upcoming TFTR D-T runs and future fusion reactors, there have been many studies to simulate the behavior of alpha particles using present D-D plasmas. One approach uses the similarity between the D-T alpha particles and the $3 \mathrm{MeV}$ protons and $1 \mathrm{MeV}$ tritons created by the D-D reactions. Using this scheme, the loss of alpha-like high energy ions has been measured under various operational conditions during the TFTR runs[1,2,8,9,11,12].

Another possible alpha simulation method employs the relatively larger population of high energy ions created during ICRF minority heating. Substantial work in this area has been done on JET[3,10] with both $\mathrm{H}$ - and ${ }^{3} \mathrm{He}$-minority heating. Specific evaluation of the $\mathrm{MeV}$ ion confinement during ICRF minority heating has been reported on JET[3] and on TFTR using ${ }^{3} \mathrm{He}$ minority heating[9].

The present report describes measurements and modeling of the loss of the high energy ions during ICRF hydrogen-minority heating, both with and without simultaneous neutral beam injection (NBI). Note that the data analyzed here was taken during the 1988-89 TFTR runs, when the ICRH power was limited to $\approx 3-4 \mathrm{MW}$. More recent $\mathrm{H}$ minority heating results at higher power have also been reported elsewhere[13]. In this paper Sec. 2 describes the data and Sec. 3 describes a simple model based on the single particle motion which may be useful to understand the underlying physics. A summary and the conclusion is given in Sec. 4.

\section{High Energy Ion Loss during H minority ICRH}

Because the fusion product protons from D-D reactions resonate at the same frequency as the hydrogen minority species does during ICRH, there are at least two possible mechanisms for high energy ion losses during ICRF wave heating:

a) the loss of D-D fusion product protons caused by ICRF waves

b) the loss of the $\mathrm{H}$ minority tail ions created by ICRF waves

Besides these direct effects of ICRF waves on the high energy ions, the ICRH could also affect the loss of these ions by changing the plasma parameters such as electron temperature and density, 
e.g. through changes in the fast-ion slowing-down time or the plasma current profile. To clarify the effects of ICRF waves on these high energy ions, we will compare the loss of these ions under plasma conditions with: a) NBI only, b) ICRH only, and c) ICRH and NBI.

However, it should be noted that for these experiments there is a much larger population of $\mathrm{H}$-minority tail ions than fusion product protons in TFTR. The production rate of the fusion protons can be deduced from the neutron signal with the branching ratio of about 1 to 1 for D-D reaction. Its value is about $2 \times 10^{15}$ neutrons/sec with several MW of NBI and less than $1 \times 10^{12}$ neutrons/sec without NBI, as shown in Fig. 2 (the neutron level of $\cong 0.4 \times 10^{12}$ neutrons/sec from 3.5 to $4.5 \mathrm{sec}$ of shot \#37132 is due to NBI onto the closed calorimeters). Since the thermalization slowing down time of a $3 \mathrm{MeV}$ proton is $\cong 0.2$ second, the total population of the fusion product protons in the vacuum vessel is about $0.4 \times 10^{15}$ particles. On the other hand, the population of $\mathrm{H}$-minority tail ions can be estimated by the following. For a 0.5 second pulse of 2 MW ICRH, the energy stored in the $\mathrm{H}$ minority tail ion is about $0.5 \mathrm{MJ}$ assuming $50 \%$ of ICRF wave coupling efficiency and no loss of the tail ions. By simply assuming $10 \%$ of the total stored energy in the tail ion is distributed uniformly between $0.5 \mathrm{MeV}$ and $1.5 \mathrm{MeV}$, the total in-vessel population of the $\mathrm{H}$ minority tail ions whose energy is above $0.5 \mathrm{MeV}$ is aivuit $3 \times 10^{17}$ particles. Though a very crude estimate, the population of $\mathrm{H}$-minority tail ion is about 100 times much larger than that of D-D fusion product protons.

\subsection{Detector System}

The two escaping high energy ion detectors discussed in this paper each consist of a pinhole/slit aperture pair which separates ions in one direction according to their pitch angle $\chi$ (measured with respect to the local toroidal field), and in the other direction according to their gyroradius $\rho$. The ions then pass through a $3 \mu \mathrm{m}$ aluminum foil which blocks any protons and tritons whose energy is below about $300 \mathrm{keV}$. The dispersed ions then hit a $\mathrm{ZnS}$ scintillator screen, which produces a visible 2-D image which is coupled to a coherent quartz or plastic fiber bundle. This 2-D light emission pattern from the scintillator can be transmitted to a video camera to get the pitch angle and gyroradius distribution of these ions loss, or to a linear array of photomultiplier tubes (PM tubes) to get their pitch angle distribution with better time resolution. The gating time of the videc camera can be varied from $\approx 10 \mu \mathrm{sec}$ to $\approx 16 \mathrm{~ms}$. More details of the diagnostic configuration and D-D fusion product loss measurement for the 1988-89 TFTR runs are described in Ref. 2. 


\subsection{The Signal Intensity and Its Time Behavior}

The measurements described below were made with the high energy ion detectors at $45^{\circ}$ and $90^{\circ}$ below the outer midplane of TFTR, as shown in Fig. 1 (i.e., detectors \#6 and \#11). The third detector at $60^{\circ}$ below the midplane generally showed the behavior intermediate between the $45^{\circ}$ and $90^{\circ}$ detectors. The midplane detector was not used for the present experiments.

Figure 3 (a) shows a typical example of the effect of ICRF H-minority heating on high energy ion losses during NBI in TFTR. This signal comes from the linear PM tube array looking at the $45^{\circ}$ detector at a pitch angle of $\chi=54^{\circ}$. About 1.9 MW of ICRF heating during 4.0-4.5 sec causes a factor of ten increase in the high energy ion loss to the $45^{\circ}$ detector, when compared to the D-D fusion product loss during $14 \mathrm{MW}$ of NBI at $3.5-4.0 \mathrm{sec}$. However, the relative increase in the loss signal in the $90^{\circ}$ detector for the same shot is much less (i.e., $\leq 30 \%$ above the NBI level), as shown in Fig. 3(b), where the signal there was monitored by the video camera (integrating over $\chi$ and $\rho$ ). In general, the additional high energy ion loss caused by the H-minority heating was strongly weighted toward the $45^{\circ}$ detector in all ICRF minority heating discharges in which the resonant layer was near the plasma center (as are all discharges discussed in this paper).

Further observations suggest that the increase of the loss signal is mostly due to the loss of ICRH tail ions, rather than to an increase in D-D fusion product loss. For example, Fig. 4 compares ion loss signals and the neutron flux signals for two discharges with the same ICRH power but different NBI powers, which means the different D-D proton populations. Shot \#37137 had 6.8 MW NBI and shot \#37139 had 4.7 MW NBI, while both shots had 1.7 MW ICRF heating. At 4.0 second, just before ICRH starts, the ion loss signal and the neutron signal from $\# 37137$ are about $40 \%$ larger than those from \#37139, which is consistent with the previous measurements of first-orbit loss of fusion product protons [2]. Between 4.0 and $4.5 \mathrm{sec}$, the loss signals for both shots increase with ICRH due to 1) increased first-orbit loss of the D-D fusion products and 2) the high energy ion loss due to ICRH.

$$
\begin{aligned}
& S_{\text {total }}(\# 37139)=S_{\text {first-orbit }}+S_{\text {ICRH }} \\
& S^{\prime} \text { total }(\# 37137)=S^{\prime} \text { first-orbit }+S^{\prime} \text { ICRH }
\end{aligned}
$$

Since the previous results show that the first orbit loss of D-D fusion products is proportional to the neutron flux signal, this first-orbit loss can be subtracted from the total loss signal. 


$$
\left(S^{\prime}-S^{\prime}\right) \text { total }=\left(S^{\prime}-S^{\prime}\right) \text { first-orbit }+\left(S^{\prime}-S^{\prime}\right) \text { ICRH }
$$

Figure 5 shows the difference of the loss signals between two shots along with the difference of the neutron flux signals. This very similar time dependence of these two curves with ICRH in Fig. 5 implies that SICRH = S'ICRH. Therefore, the increased high energy ion loss signal is mainly due to the H-minority tail ions created by ICRF waves, because if it came from the loss of D-D fusion products expelled by ICRF waves, there should be a larger increase in the loss signal for the shot with higher NBI and more D-D fusion products.

There are large variations in the high energy ion loss signal intensity with different heating schemes and at different poloidal locations of detectors. The table below shows the relative intensity of loss signals (there is no relation between the signal intensity of two different detectors).

\begin{tabular}{|l|l|l|l|}
\hline Relative Intensity & & $\begin{array}{l}45^{\circ} \text { detector } \\
(\text { camera })\end{array}$ & $\begin{array}{l}90^{\circ} \text { detector } \\
(\text { PM tube })\end{array}$ \\
\hline NBI only (\#37143) & $6.8 \mathrm{MW}$ & $<1$ & 5 \\
\hline ICRH only (\#37132) & $1.7 \mathrm{MW}$ & 3 & 0.5 \\
\hline ICRH + NBI (\#37144) & $1.7 \mathrm{MW}+4.7 \mathrm{MW}$ & 150 & 10 \\
\hline
\end{tabular}

Figure 6 shows a discharge (\#37132) with $1.7 \mathrm{MW}$ of ICRH-only which has a clear ICRH tail ion loss at a very low neutron rate of $1 \times 10^{12}$ neutrons/sec, while the loss signal for a NBI-only discharge(\#37143) is too small to be shown due to the faster gating time of the video camera in the $45^{\circ}$ detector (the neutron signals from both shots are shown in Fig. 1). However, as in Fig. 7, it is clear that the ICRH tail ion loss in the $90^{\circ}$ detector is very small compared to the first-orbit loss of D-D fusion protons. This poloidal angle distribution of ICRH tail ion losses will be discussed in Sec. 3.

There is also a large difference in the relative intensity of the loss signals due to ICRH with and without NBI, as shown in Fig. 6 and Fig. 8. Figure 8 (a) is from the PM tube data at $\chi=54^{\circ}$ in the $90^{\circ}$ detector, and Fig. 6 and Fig. 8 (b) are from the video camera on the $45^{\circ}$ detector. The ICRH power for shots \#37132 and \#37144 is $1.7 \mathrm{MW}$ and the shot \#37144 has 6.8 MW NBI. This large difference in the loss signals can be understood by the exponential dependence of the tail ion distribution on the tail ion temperature. Because the tail ion temperature is proportional to the slowing down time due to the electron drag, which is a function of the electron density and temperature, the tail ion temperature of the shot with NBI (\#37144) is about six times higher than 
that of the shot without NBI (\#37132), based on the electron temperature and density data for these shots given in Fig. 9. Thus, there would be a factor of about 100 difference in the tail ion population whose energy is above $300 \mathrm{keV}$, assuming the same hydrogen density for both shots $[4,6]$.

It takes about 0.1 to $0.3 \mathrm{sec}$ for the loss signal to reach a steady level after the ICRF wave launch. This time delay is expected for the formation of the ICRH tail ions. The time dependence of the high energy ion loss and the electron temperature is shown in Fig. 10. Since the NBI also changes the electron temperature, the data from the NBI only case is used as a reference. Both the ion loss and the electron temperature signals rise similarly after ICRH starts and reachs a steady level in $0.3 \mathrm{sec}$. Note that the loss signal drops very quickly at $4.5 \mathrm{sec}$ when ICRF waves are turned off.

\subsection{The Pitch Angle and Energy Distribution of the Loss}

The pitch angle and energy distribution is very similar for the ICRH induced loss with and without NBI. Figure 11 shows the pitch angle distribution in the $90^{\circ}$ detector from the shots with: 1) NBI only, 2) ICRH only, and 3) ICRH and NBI. The similarity of the pitch angle distributions between 2) and 3) reinforces the idea that the loss signal from ICRH with NBI is just the ICRH tail ion loss without any deconfinement of the D-D fusion product protons. Note that the pitch angle distribution of the loss signal in the $90^{\circ}$ detector shifts toward lower angle by 3-4 degrees with ICRH. The pitch angle and energy distribution in the $45^{\circ}$ detector is similar between ICRH only shots and ICRH + NBI shots, as shown in Fig. 12.

\subsection{Summary of Measurements}

1) ICRF H-minority heating generates a clear increase of the high energy ion loss signals in both the $45^{\circ}$ detector and $90^{\circ}$ detector (Figs. 3 and 8).

2) These increases of the high energy ion loss signal due to ICRH are most likely from the ICRH tail ions (Figs. 4 and 5).

3) There are large variations in the high energy ion loss signal intensity with different heating methods and at different poloidal locations of detectors (Figs. 6,7,8 and 9).

4) The ICRH induced high energy ion loss is strongly concentrated on just below the outer mid-plane, i.e., at the $45^{\circ}$ detector. This poloidal angle distribution of the ICRH induced high energy ion loss will be discussed in Sec. 3 (Figs. 6,7 and 8). 
5) There is about a 0.1 to $0.3 \mathrm{sec}$ time delay for the high energy ion loss signal after the ICRF wave launch. This time delay is expected for the formation of the ICRH tail ions (Fig. 10).

6) The similar pitch angle and energy distribution of the high energy ion loss signal for the ICRH induced loss, with and without NBI, reinforces the idea that the loss signal comes from the ICRH tail ion loss without any deconfinement of the D-D fusion product protons (Figs. 11 and 12).

The total loss of ICRH tail ions can be estimated from the following argument. The expected D-D fusion product loss without ICRH is about $800 \mathrm{~W}$ for a source strength of $6 \times 10^{15}$ neutrons/sec (Fig. 2), assuming a $20 \%$ first-orbit loss at $I_{p} \approx 1.2 \mathrm{MA}$ [1]. The loss signal increases $20 \%$ in the 90 degree detector and about 10 times in the $45^{\circ}$ detector during ICRH. Therefore, we can set up the reasonable upper limit of the loss of ICRH tail ions as $\mathrm{P}_{\text {loss }}<50$ $\mathrm{kW}$, even though the absence of the detector near the midplane makes it difficult to evaluate the poloidal distribution of the loss by ICRH waves. This power loss of ICRH tail ions is only a very small fraction of total ICRH power $\left(P_{R F}=1.9 \mathrm{MW}\right.$ for this shot), and so suggests a good confinement of ICRH tail ions.

\section{Modeling the effect of ICRF waves on high energy ions}

The following simple model for the effect of ICRF waves on high energy ions, based on the single particle motion, incorporates two basic assumptions from ICRF wave heating theory $[4,5,6]$ :

1) the resonance between charged particles and ICRF waves happens when the particle's cyclotron frequency is equal to the ICRF wave frequency. Since the magnetic field is not constant along the particle trajectory, the resonance is confined within a narrow strip along the vertical axis generally passing through the plasma center.

2) the heating effect of ICRF waves is mostly to increase the fast ion's velocity perpendicular to the magnetic field.

Along with these basic assumptions, there are two approximations that greatly simplify the model: (1) infinitesimal thickness of the resonance layer and (2) neglect of the finite gyroradius effects. The large thermal velocity of high energy ions will broaden the width of the resonance layer and change the direction of wave heating due to Doppler shift. In addition to that, the large gyroradius 
will affect the wave-particle interaction through $\mathrm{k}_{\perp} \rho$ correction. However, as a lowest order approximation, the above conditions are still valid $\left(\mathrm{v}_{\mathrm{th}} / \mathrm{v}_{\mathrm{ph}}<1\right.$ and $\left.\mathrm{k}_{\perp} \rho<1\right)$.

The single particle motion consists of 6 degrees of freedom in phase space, but by finding any constant of motion, we can reduce its degree of freedom. We will assume symmetry in the toroidal direction in configuration space and argue that the velocity space can be two dimensional instead of three by ignoring the gyrophase.

An unperturbed trajectory of a particle may have two or four intersecting points with the resonance layer depending on its energy and pitch angle (two for a passing orbit and four for a trapped particle as shown in Fig. 13. If the particle trajectory does not intersect with the resonance layer, it will not be affected by the ICRF waves in the first approximation) and the vertical positions of these intersecting points will not change in the absence of ICRF waves. Because of the infinitesimal thickness of the resonance layer, the effect of ICRF waves is to change the particle velocity instantaneously when the particle crosses the resonance layer. By symmetry, the vertical positions of the passing particle's intersecting points will not change due to the ICRF waves. For a trapped particle which has four intersecting points, the positions of the intersecting points change in the following manner. ICRF wave heating at the inner intersecting point (when the particle is counter-going), will move the next outer intersecting point outward and the ICRF wave heating at the outer intersecting point (when the particle is co-going) will move the next inner intersecting point inward due to the fatter banana orbit. Since the vertical positions of the intersecting points are quite insensitive to the velocity changes (for example, $2-3 \mathrm{~cm}$ in the vertical position shift corresponds to 200-300 keV energy gain per bounce), and these inward and outward shifts approximately cancel each other, we will assume that the particle trajectory keeps the same vertical intersection points with the resonance layer while the particle is accelerated by ICRF waves. The average energy gain per bounce in TFTR is only about $10 \mathrm{eV}$ according to the present ICRH theory [6].

This constancy of the vertical positions of intersecting points provides two constants of motion in configuration space and will be utilized as an initial condition in the code. In addition to those, the particle trajectory in $(\chi, E)$ space during ICRH is given in Eq. (4).

$$
\begin{aligned}
& 1+\tan ^{2} \chi=1+\mathrm{v}_{\perp} 2 / \mathrm{v}_{\mathrm{pa}}{ }^{2}=\mathrm{E} / \mathrm{mv}_{\mathrm{pa}}{ }^{2} \\
& 2 \tan \chi \mathrm{d}(\tan \chi)=\mathrm{dE} / \mathrm{mv}_{\mathrm{pa}}{ }^{2} \\
& \cos ^{2} \chi=\mathrm{v}_{\perp}^{2 / \mathrm{v}^{2}}=\mathrm{mv}_{\mathrm{pa}}{ }^{2} / \mathrm{E} \\
& \mathrm{d}(\chi) / \mathrm{dE}=\cot (\chi) / 2 \mathrm{E}
\end{aligned}
$$


where $\chi$ is a pitch angle defined as the angle between the particle velocity and the local magnetic field (hereafter we use $\chi$ to indicate the angle between the particle velocity and the local toroidal magnetic field), $\mathrm{E}$ is particle energy. $\mathrm{v}_{\mathrm{pa}}$ and $\mathrm{v}_{\perp}$ are parallel and perpendicular velocity of the particle to the total magnetic field. To get this simple equation, we have assumed that the energy changes only in directions perpendicular to the magnetic field.

Using these constants of motion, we run the Lorentz particle orbit code of TFTR (called ORBIT) to get a phase space $(\chi, E)$ diagram of the proton loss region at different vertical positions in the resonance layer. The plasma conditions including B-field and plasma current profiles are taken from the TFTR Snap code result of the shot \#37139. Figure 14 shows general features of the loss region. The protons start their orbits at a major radius of $270 \mathrm{~cm}$ and a height of 10,15 , 20,25 , and $35 \mathrm{~cm}$ below the midplane, with their initial velocity $V_{R}=V \sin (\chi), V_{\varnothing}=V \cos (\chi), V_{Z}=$ 0 . This particular choice of initial positions was made to simulate the trajectory of the particles starting from the resonance layer. The toroidal coordinates $(\mathrm{R}=$ major radius, $\varnothing=$ toroidal angle, and $\mathrm{z}=$ vertical height from the midplane) are used. The arrows, drawn according to Eq. (4), summarize the effect of ICRH and indicate the direction of particle motion in $(\chi, E)$ space (the size of arrows is enlarged to show the direction clearly), assuming no change in its vertical positions of the intersecting points with the resonance layer. Note that average energy gain of resonant ions per bounce is only about $10 \mathrm{eV}$ as mentioned earlier.

As seen in Fig. 14, the loss region changes for different poloidal angles at the wall, and two different curves divide the loss region from the rest of the $(\chi, \mathrm{E})$ space. The upper boundary corresponds to the high energy ion loss at midplane and the lower curve is the passing-trapped boundary which was previously discussed in Ref. 2

The shape of the loss region suggests that there would be little D-D fusion proton loss due to ICRF waves. D-D fusion protons whose energy at birth is around $3 \mathrm{MeV}$ will either hit the vacuum vessel during their first-orbit or stay inside plasma with higher or lower pitch angle than the angle defining the loss boundary. Since ICRF waves cannot heat the passing particles very effectively [5], most of the particles with lower pitch angle will stay inside the plasma and become thermalized. The particles with higher pitch angle will be slowed down due to electron drag while they keep their pitch angle. Since the curve defining the upper boundary of the loss region has positive slope, they have to be accelerated above their birth energy to be lost. This is unlikely to happen and confirms the measurement that there is little D-D fusion product proton loss due to ICRF waves. 
On the other hand, the existence of the gap between the loss boundary and the loss curve corresponding to a different poloidal angle at the wall explains the poloidally weighted high energy ion loss of ICRH tail ions. The high energy ions heated by ICRF waves will eventually move to the upper boundary and immediately after these ions cross the upper boundary, they will hit the vacuum vessel. Since the size of the gar represents the distance in phase space the particles should cross within their last bounce in plasma to be lost to that specific poloidal location, there would be more particles to be lost at lower poloidal angle with respect to the midplane than at a higher poloidal angle.

However, as seen in Fig. 14, the gap spacing is very large, even though it decreases as the inner vertical intersecting position moves farther from the plasma center. The proton would need to gain at least more than $100 \mathrm{keV}$ on its last bounce inside the plasma in order to hit the $45^{\circ}$ detector when its banana tip was located at $35 \mathrm{~cm}$ below the midplane. The plasma heating by ICRF wave already becomes small at this position, due to the focusing of ICRF heating to the plasma center. These large gaps raise a question about the mechanism of the high energy ion loss by ICRF waves, since the particles should move to the corresponding curve in the loss region just before they escape the plasma in order to hit the $45^{\circ}$ or $90^{\circ}$ detector.

One possible explanation for this apparent anomaly is toroidal field (TF) ripple induced loss[8]. The banana tip locations of the trapped particles' orbits move to the plasma edge as the positions of these particles in $(\chi, E)$ space approach the upper boundary of the loss region because the banana orbit becomes fatter. If TF ripple near the plasma edge is strong enough to move this banana tip outward, the particles can be lost to the $45^{\circ}$ detector. Along with this, as seen in Fig. 14 , if the particles can move about $5-10 \mathrm{~cm}$ radially, they can also hit the $45^{\circ}$ detector. There is a possibility that the sawtooth crash can expel the tail ions from the plasma center [10]. However, there was no evidence of sawtooth for most of the shots we used to measure the high energy ion loss. Also, we did not see any of MHD mode activity in the shots analyzed[12].

\section{Conclusion}

These measurements of the $\mathrm{MeV}$ ion loss during ICRF wave hydrogen minority heating suggest that the loss comes mostly from the ICRH tail ions. The loss of high energy ions due to ICRH is strongly weighted toward lower poloidal angles with respect to the outer midplane. However, a decisive conclusion about the effects of ICRF waves on the fusion product protons 
cannot yet be made since the population of ICRH tail ions is about 100 times larger than that of D$\mathrm{D}$ fusion products during these measurements.

A simple model based on the single particle motion in phase space $(\chi, E)$ of the effect of ICRF waves on high energy particles was discussed. The model suggests that there should be only a small deconfinement of D-D fusion product protons due to ICRF waves and explains the poloidal distribution of the high energy ion loss. However, this model predicts high energy ion loss very near to the midplane, while the measurements show the substantial Joss around the $45^{\circ}$ below midplane and somewhat small but clear signal of the loss even at the $90^{\circ}$ below midplane. This inadequacy of the simple model suggests that there may be other mechanisms such as TF ripple which can cause substantiai loss around $45^{\circ}$ below the outer midplane. However, in order to understand the loss mechanism, the measurement of the loss at the midplane should be made along with the measurement at the $45^{\circ}$ and $90^{\circ}$ detectors.

\section{Acknowledgment}

We thank to G.W. Hammett and C.S. Chang for valuable discussions about ICRH theory, M. Diesso for his help in analyzing the loss data, J. Felt for her help with the ORBIT code, and R.J. Wilson and C.-K. Phillips for creating the ICRF-heated plasmas analyzed here. This work was supported by US Department of Energy Contract \# DE-AC02-CHO-3073. 


\section{REFERENCES}

[1] ZWEBEN, S.J., et al., Proc. of 14th Int'l Conf. on Plasma Physics and Cont. Nucl. Fusion Research, Wurzburg, IAEA. (1992) paper IAEA-CN-56/A-63

[2] ZWEBEN, S.J., BOIVIN, R.L., DIESSO, M., et al., Nucl. Fusion 30 (1990) 1551

[3] COTTRELL, G.A., START, D.F.H., Nucl. Fusion 31 (1991) 61

[4] STIX, T.H., Nucl. Fusion 15 (1975) 737

[5] HAMMETT, G.W., Ph.D. Thesis, Princeton University, 1986

[6] CHEN, L., VACLAVIK, J., HAMMETT, G.W., Nucl. Fusion 28 (1988) 389

[7] START, D.F.H., et al., JET report JET-P(91)06

[8] BOIVIN, R.L., et al., Nucl. Fusion 33 (1993) 449

[9] ZWEBEN, S.J., HAMMETT, G.W., BOIVIN, et al., Nucl. Fusion 32 (1992) 1823

[10] SADLER, G., et al., Fusion Technology 18 (1990) 556

[11] ZWEBEN, S.J., STRACHAN, J.D., BOIVIN, R., et al., EPS Venice 1989

[12] ZWEBEN, S.J., DARROW, D.S., BUNDY, R.V., et al., Princeton Plasma Physics Laboratory Report PPPL-2934 (1993)

[13] WILSON, J.R., BELL, M.G., BIGLARI, H., et al, Princeton Plasma Physics Laboratory Report PPPL-2890(1993) 


\section{Figure Captions}

Fig. 1 Location of high energy escaping ion detectors in TFTR. The detector \#11 is at $45^{\circ}$ below the midplane, and the \#6 detector is $90^{\circ}$ below the midplane. The \#9 and midplane detector were not used for this experiment.

Fig. 2 Part (a) shows the neutron flux signal of \#37132 (1.7 MW ICRH-only shot) and part (b) is about the neutron flux of \#37143 (6.8 MW NBI-only shot). The neutron level (@ 0.4x1012 neutrons/sec) of the shot \#37132 from 3.5 to $4.5 \mathrm{sec}$ is due to NBI onto the closed calorimeters. This neutron flux signal is used to estimate the D-D fusion product proton population.

Fig. 3 Time behavior of the MeV ion loss signal in shot \#43935 which has both NBI and ICRF hydrogen minority heating $\left(\mathrm{R}=2.6 \mathrm{~m}, \mathrm{~B}=3.3 \mathrm{~T}, \mathrm{I}_{\mathrm{p}}=1.1 \mathrm{MA}\right)$. Part (a) shows the loss signal in the $45^{\circ}$ detector at $\chi \approx 54^{\circ}$, as measured using PM tubes, while part (b) shows the loss signal in the $90^{\circ}$ detector for the same shot, measured using the video camera. Neutron flux data is used for comparison with the expected D-D fusion product first-orbit loss.

Fig. 4 Neutron flux and high energy ion loss signals in the $45^{\circ}$ detector for discharges with $\mathrm{B}=3.3 \mathrm{~T}$ and $\mathrm{I}_{\mathrm{p}}=1.2 \mathrm{MA}$. The ion loss signals were measured using the same PM tubes at $\chi \approx 54^{\circ}$ for both shots \#37137 (with 4.7 MW NBI and 1.8 MW ICRH) and \#37139 (with 6.8 MW NBI and 1.8 MW ICRH). NBI started at $3.5 \mathrm{sec}$ and ended at $4.5 \mathrm{sec}$ with ICRH turned on during 4.0 $\sec$ to $4.5 \mathrm{sec}$ for both shots (however, the NBI power is different). The increased loss signals consist of two different parts such as 1) first-orbit loss and 2) high energy ion loss due to ICRH. The first-orbit loss signal is proportional to the neutron flux signal and can be subtracted from the total loss signal.

Fig. 5 Differences between the neutron flux and the high energy ion loss signals in the shots \#37137 and \#37139. The close similarity between two curves indicates that the increases of high energy ion loss only due to ICRH for both shots are equal in magnitude, while their D-D fusion product populations are different.

Fig. $6 \mathrm{MeV}$ ion loss signal in the $45^{\circ}$ detector for the shot \#37132 (ICRH-only shot) measured using the video camera. It comes from the loss of ICRH tail ions because the low neutron level indicates that there is very few $\mathrm{D}-\mathrm{D}$ fusion products. The $\mathrm{MeV}$ ion loss signal for the shot 
\#37143(NBI-only shot) in the same detector is too small to be shown due to the shorter gating time of the video camera during the shots. Note that the same gating time is used for both shots.

Fig. $7 \mathrm{MeV}$ ion loss signal for \#37132 and \#37143 in the $90^{\circ}$ detector measured using $\backslash \mathrm{PM}$ tubes at $\chi=54^{\circ}$. Unlike the $45^{\circ}$ detector which showed a stronger signal for \#37132 (ICRH only), the loss from \#37143 (NBI only) is much larger than that of \#37132. This poloidal angle dependence of the loss signal from ICRH tail ions will be explained in Sec. 3.

Fig. 8 Part (a) shows the MeV ion loss signals in the $90^{\circ}$ detector for shots \#37132 and \#37144 measured using PM tube at $\chi=54^{\circ}$ and Part (b) shows the high energy ion loss in the $45^{\circ}$ detector measured using the video camera (the same gating time and scale is used for both \#37132 and \#37144 as shown in Fig. 8 (b) and Fig. 6). The large difference in the signal intensity is due to the different plasma conditions, such as electron temperature and density, on which the ICRH tail ion population strongly depends.

Fig. 9 Electron temperature and line density measurements for the shots \#37132 and \#37144. The electron temperature was measured at $R_{\text {major }}=282 \mathrm{~cm}$ and the line density was measured at $\mathrm{R}_{\text {major }}=268 \mathrm{~cm}$.

Fig. 10 Time dependence of the loss signal in the $45^{\circ}$ detector and the electron temperature from the shot \#37137. The shot \#37143 (NBI-only) is used as a reference. The loss signals were measured using PM tubes and the electron temperature data were measured at $R_{\text {major }}=282 \mathrm{~cm}$.

Fig. 11 Pitch angle distribution of the $\mathrm{MeV}$ ion loss in the $90^{\circ}$ detector for three different shots; a) NBI-only (\#37143), b) ICRH-only (\#37132), and c) ICRH and NBI (\#37146́). All signals were measured using PM tubes. Note that a different $y$-axis scale is used for the shot \#37132.

Fig. 12 Pitch angle and gyro-radius distributions of the $\mathrm{MeV}$ ion loss in the $45^{\circ}$ detector for two different shots; (a) \#37132 (ICRH only) and (b) \#37146 (ICRH with NBI). All signals were measured using the video camera.

Fig. 13 Poloidal projection of proton orbit in TFTR. Part (a) is about the $3 \mathrm{MeV}$ passing particle orbit which has two intersections with the resonance layer and part (b) is about the $0.5 \mathrm{MeV}$ trapped particle orbit which has four intersections. Both particle have the same pitch angle of $60^{\circ}$. 
at their initial position marked in the figure. $\mathrm{I}_{\mathrm{p}}=1.2 \mathrm{MA}, \mathrm{BT}=3.25 \mathrm{~T}, \mathrm{R}_{\text {major }}=2.6 \mathrm{~m}$, and the current profiles are taken from the TFTR Snap code result.

Fig. 13 High energy ion loss regions in $(\chi, E)$ space for different vertical positions; (a) - (e) : $\mathrm{R}_{\text {major }}=270 \mathrm{~cm}$ and height $=10,15,20,25,35 \mathrm{~cm}$ below the midplane. The arrows are drawn to indicate the direction of particle's motion during ICRF wave heating. The size of arrows are greatly enlarged to show the direction clearly. The average energy gain of particle per bounce is only about $10 \mathrm{eV}$. 


\begin{tabular}{|r|r|l|l|l|l|l|l|l|}
\hline & shot \# & 45 detector & 90 detector & RF power(MW) & NBI power(MW) & plasma current & TF current & gases \\
\hline 0 & 37132 & camera & PM tube & 1.7 & NO & $1.2 \mathrm{MA}$ & $48.8 \mathrm{kA}$ & $\mathrm{D}+\mathrm{H}$ minority \\
\hline 1 & 37136 & camera & PM tube & 0.3 & 6.8 & $1.2 \mathrm{MA}$ & $48.8 \mathrm{kA}$ & $\mathrm{D}+\mathrm{H}$ minority \\
\hline 2 & 37137 & camera & PM tube & 1.7 & 6.8 & $1.2 \mathrm{MA}$ & $48.8 \mathrm{kA}$ & $\mathrm{D}+\mathrm{H}$ minority \\
\hline 3 & 37139 & camera & PM tube & 1.7 & 4.7 & $1.2 \mathrm{MA}$ & $48.8 \mathrm{kA}$ & $\mathrm{D}+\mathrm{H}$ minority \\
\hline 4 & 37143 & camera & PM tube & $\mathrm{NO}$ & 6.8 & $1.2 \mathrm{MA}$ & $48.8 \mathrm{kA}$ & $\mathrm{D}+\mathrm{H}$ minority \\
\hline 5 & 37144 & camera & PM tube & 1.7 & 4.7 & $1.2 \mathrm{MA}$ & $48.8 \mathrm{kA}$ & $\mathrm{D}+\mathrm{H}$ minority \\
\hline 6 & 37146 & camera & PM tube & 1.7 & 4.7 & $1.2 \mathrm{MA}$ & $48.8 \mathrm{KA}$ & $\mathrm{D}+\mathrm{H}$ minority \\
\hline 7 & & & & & & & & \\
\hline 8 & 43932 & PM tube & camera & NO & 14 & $1.1 \mathrm{MA}$ & $48.0 \mathrm{kA}$ & $\mathrm{D}+\mathrm{H}$ minority \\
\hline 9 & 43933 & PM tube & camera & 1.4 & 12 & $1.1 \mathrm{MA}$ & $48.0 \mathrm{kA}$ & $\mathrm{D}+\mathrm{H}$ minority \\
\hline 10 & 43934 & PM tube & camera & 1.7 & 14 & $1.1 \mathrm{MA}$ & $48.0 \mathrm{KA}$ & $\mathrm{D}+\mathrm{H}$ minority \\
\hline 11 & 43935 & PM tube & camera & 1.9 & 14 & $1.1 \mathrm{MA}$ & $48.0 \mathrm{kA}$ & $\mathrm{D}+\mathrm{H}$ minority \\
\hline 12 & 43937 & PM tube & camera & 2.8 & 14 & $1.1 \mathrm{MA}$ & $48.0 \mathrm{KA}$ & $\mathrm{D}+\mathrm{H}$ minority \\
\hline 13 & 43938 & PM tube & camera & 3.0 & 14 & $1.1 \mathrm{MA}$ & $48.0 \mathrm{kA}$ & $\mathrm{D}+\mathrm{H}$ minority \\
\hline 14 & 43939 & PM tube & camera & 3.3 & 14 & $1.1 \mathrm{MA}$ & $48.0 \mathrm{KA}$ & $\mathrm{D}+\mathrm{H}$ minority \\
\hline 15 & 43946 & Pm tube & camera & 2.3 & 14 & $1.1 \mathrm{MA}$ & $48.0 \mathrm{kA}$ & $\mathrm{D}+\mathrm{H}$ minority \\
\hline
\end{tabular}

Table 1

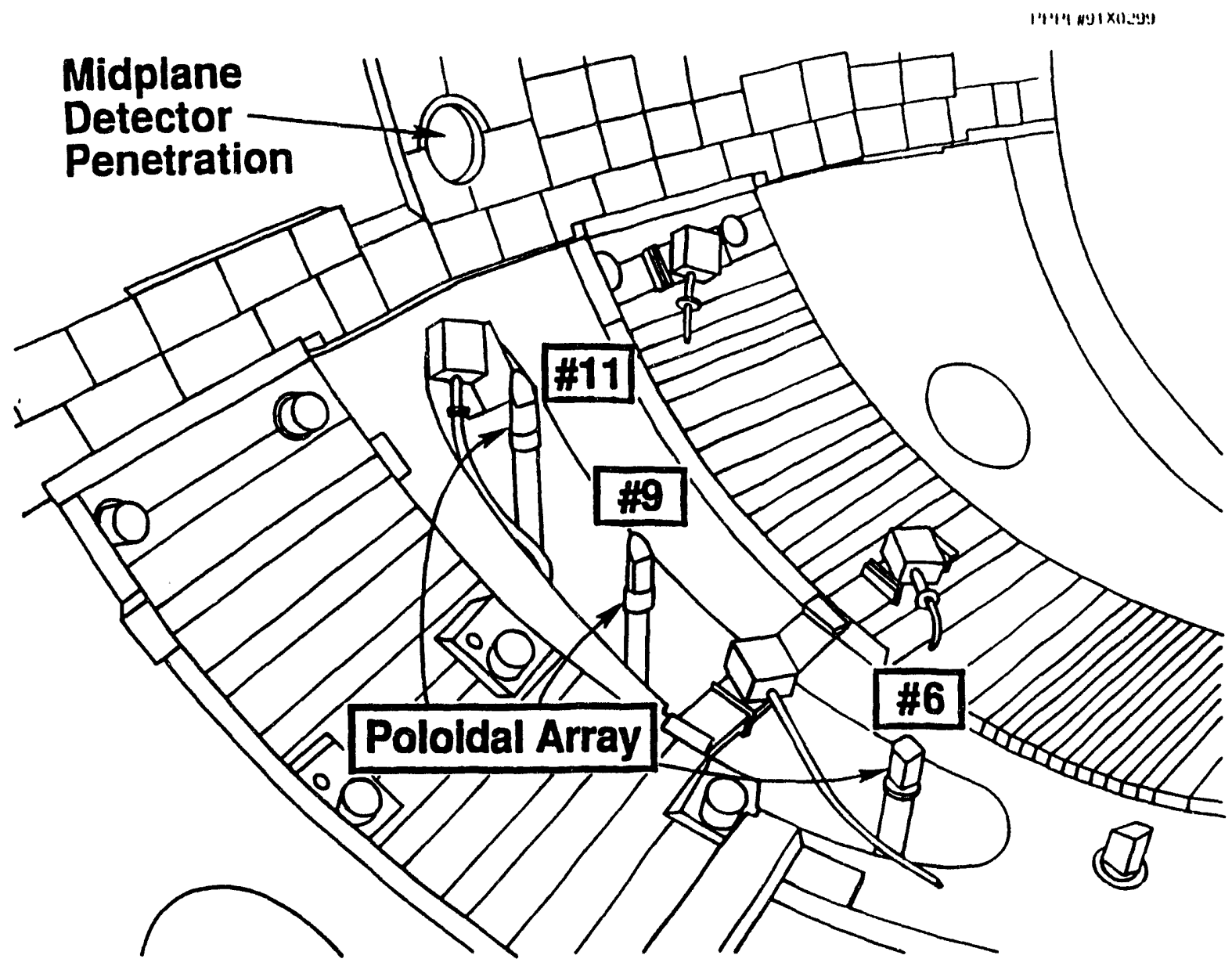

Fig. 1 


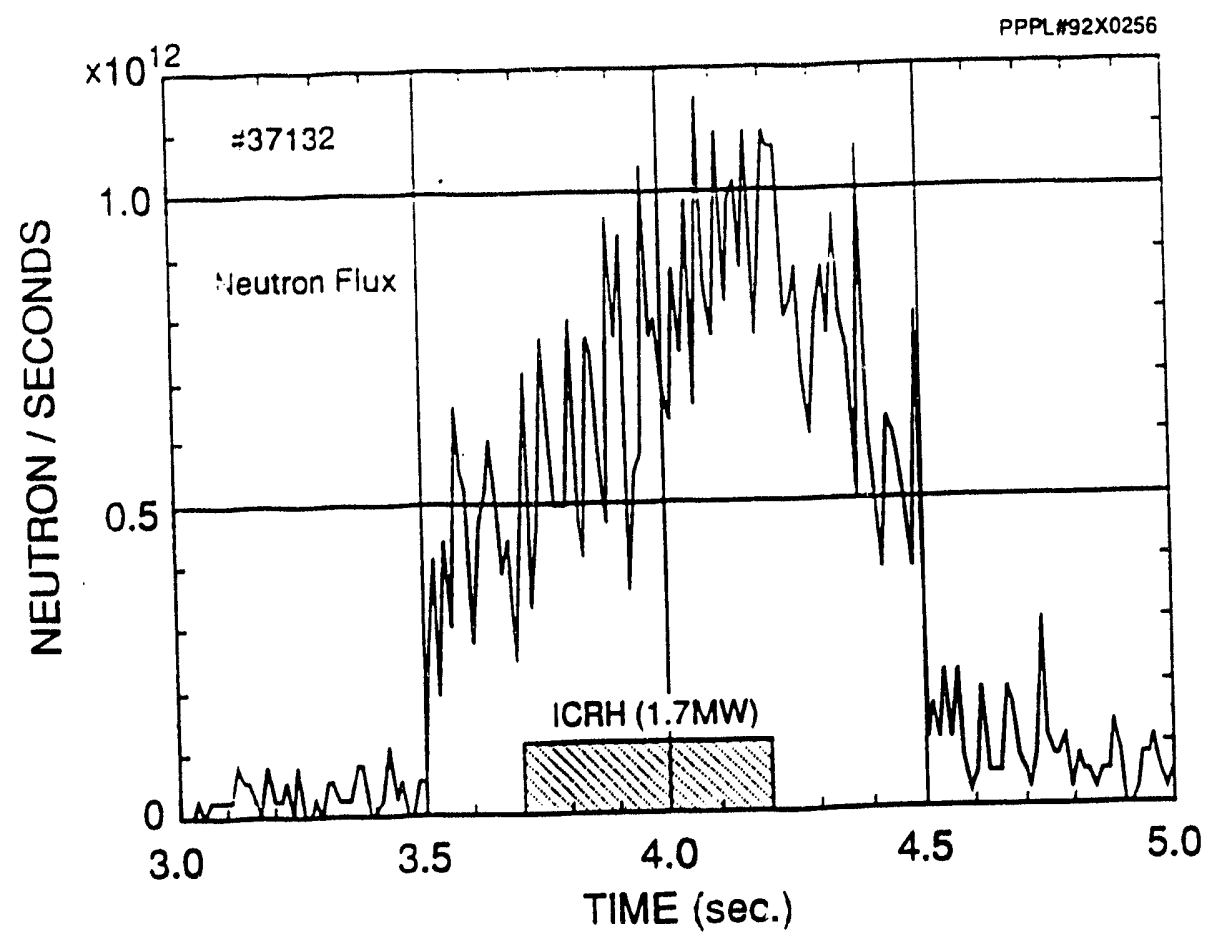

Fig. 2 (a)

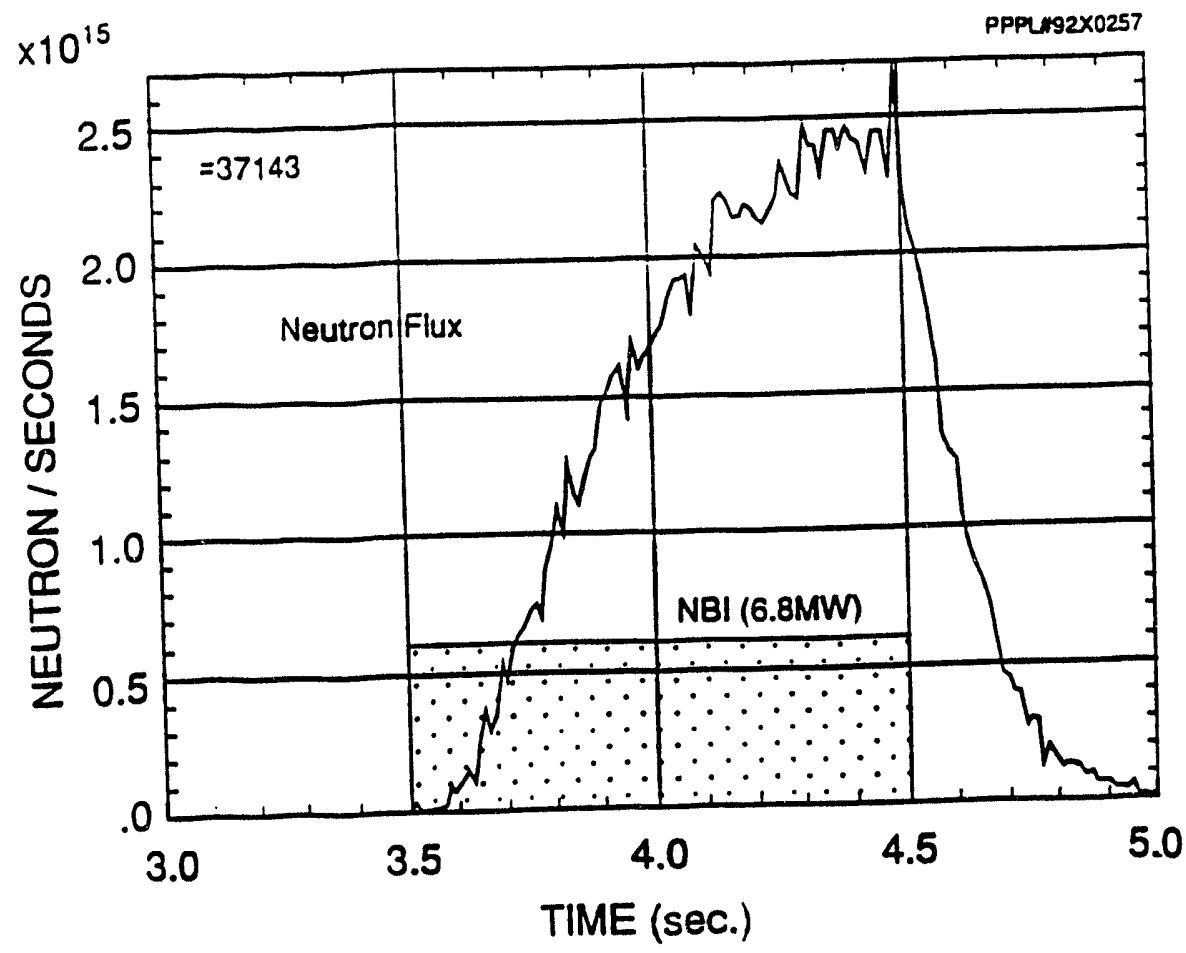

Fig. 2 (b) 


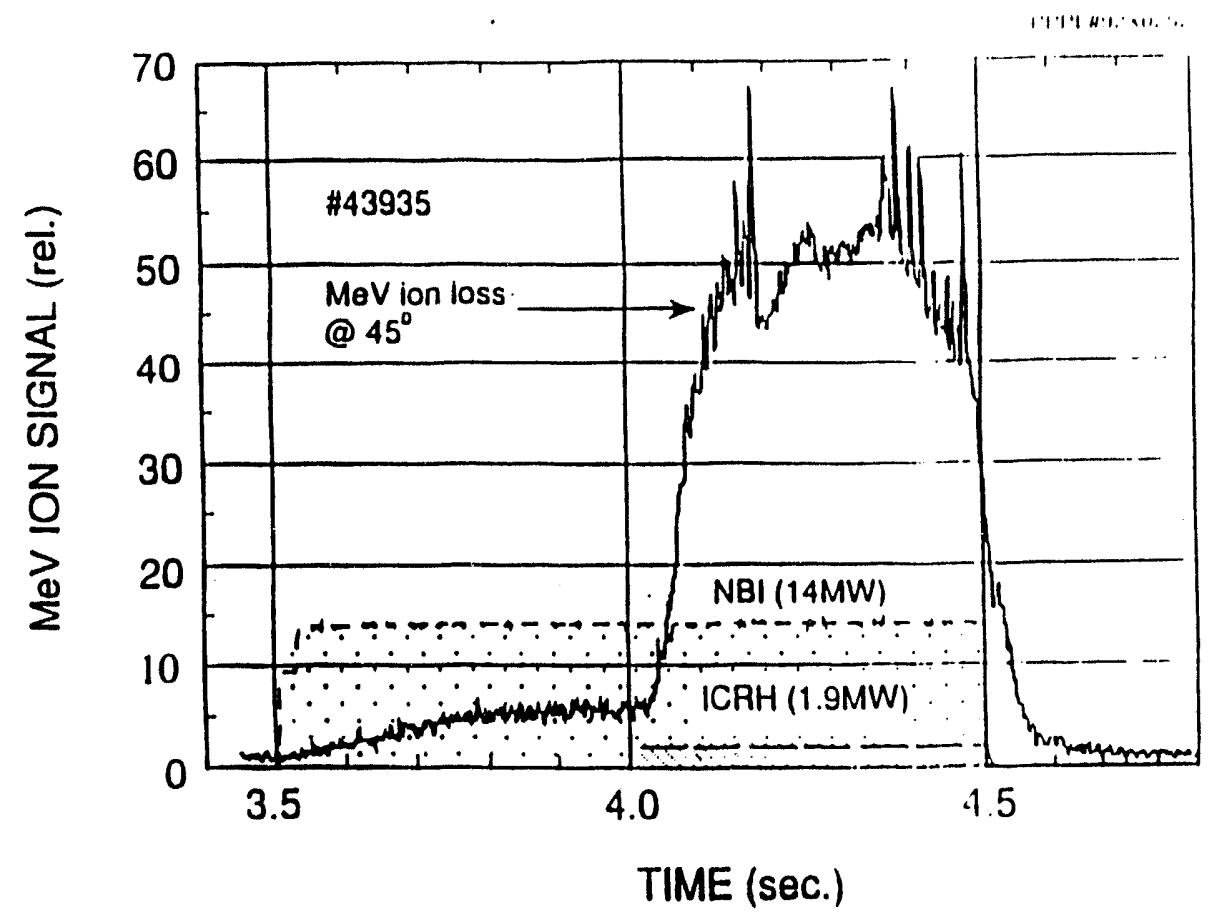

Fig. 3 (a)

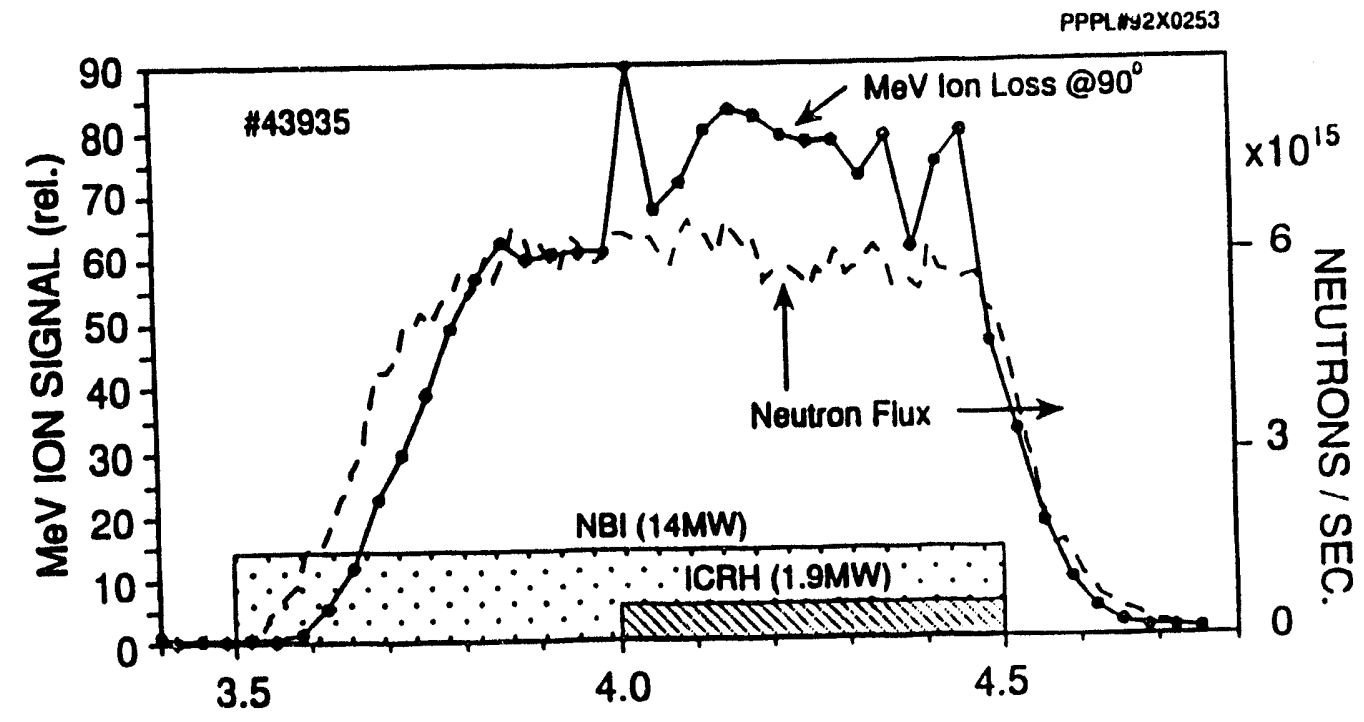

Fig. 3(b) 

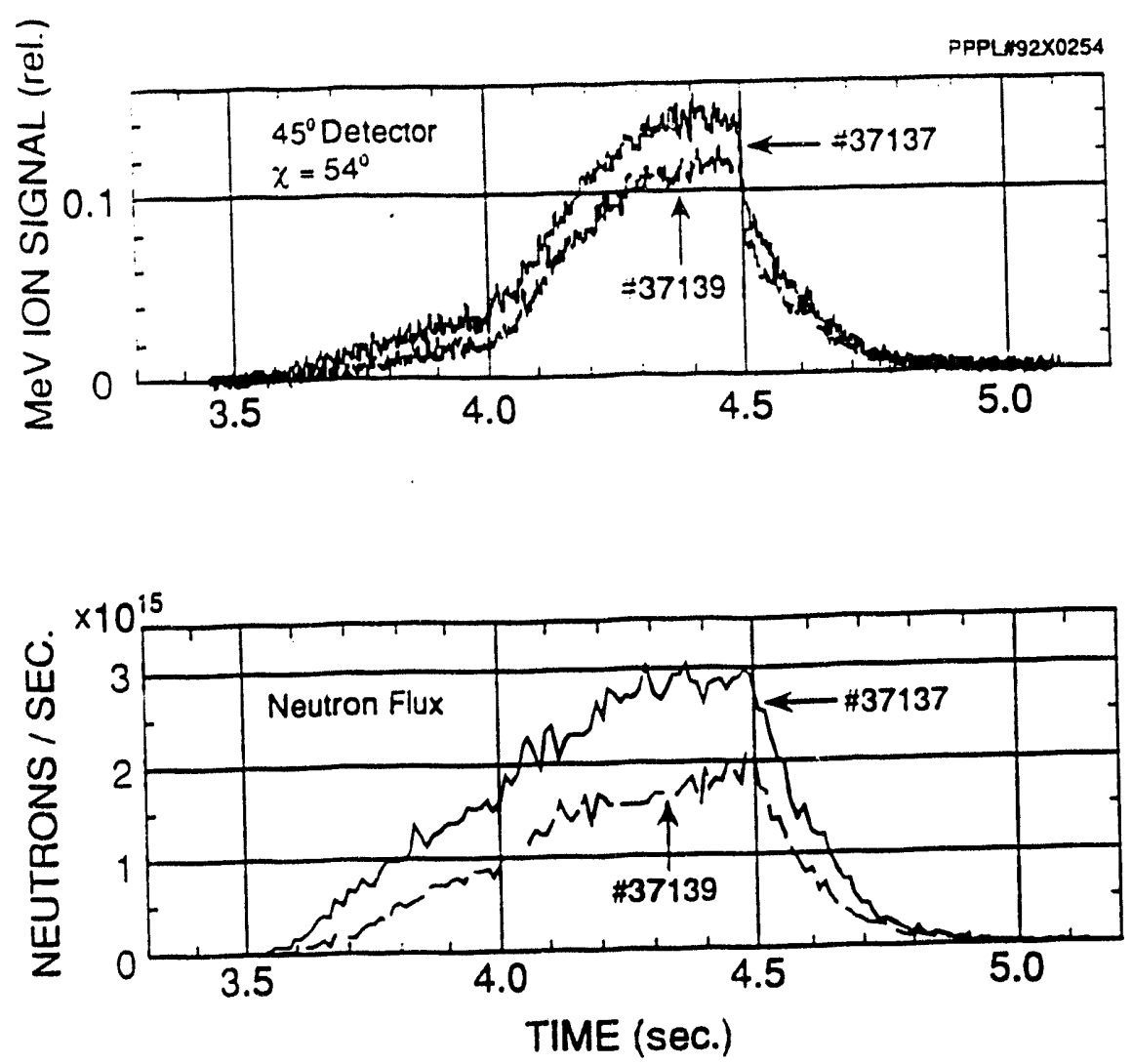

Fig. 4
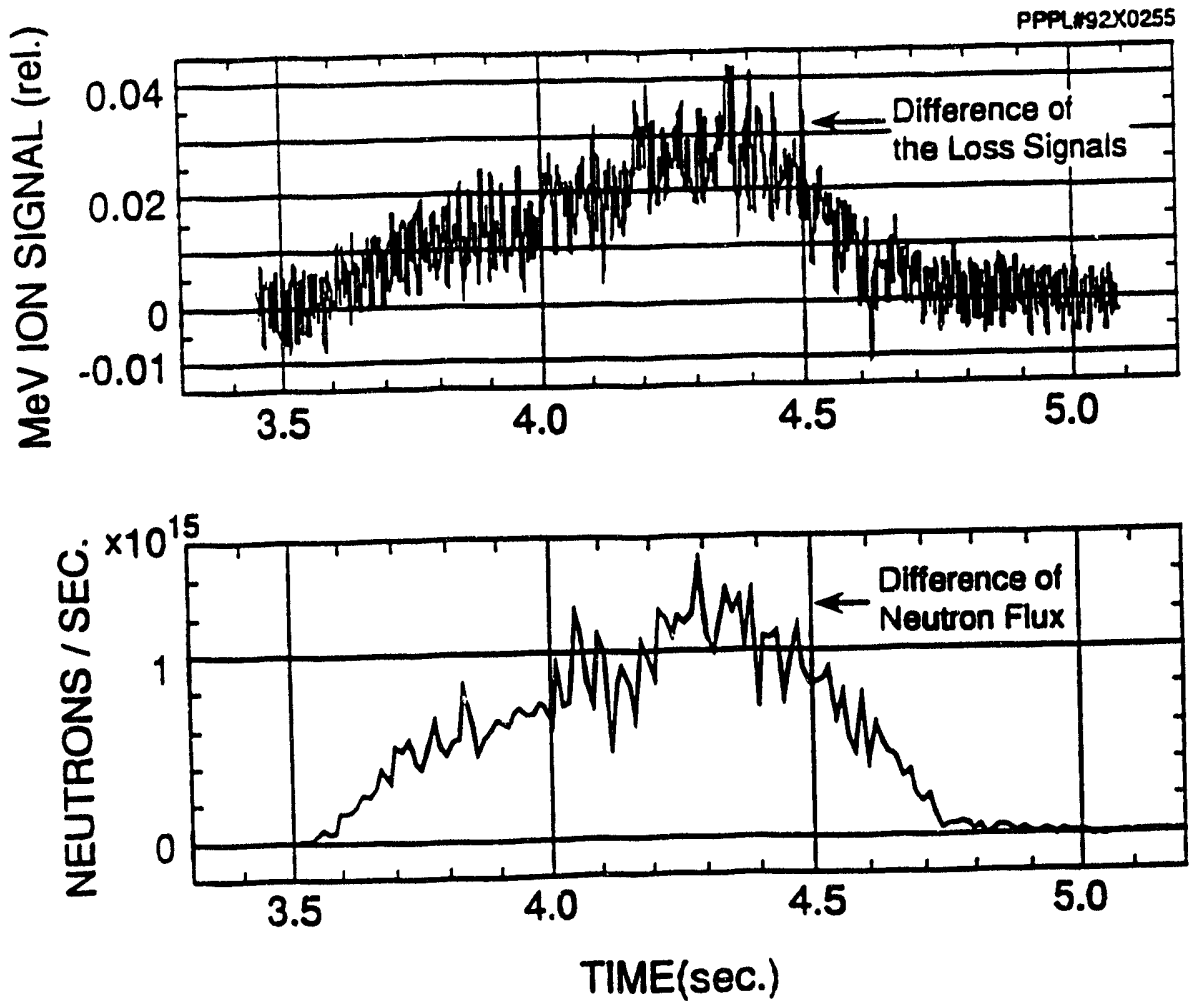

Fig. 5 


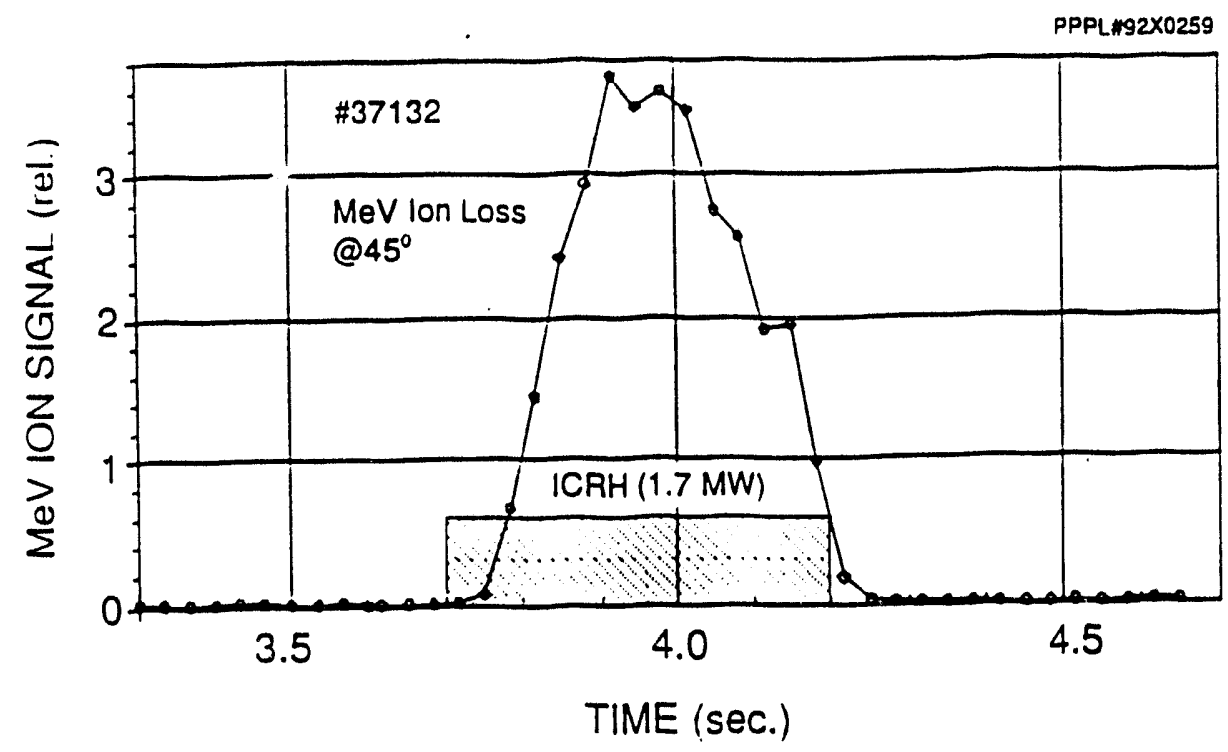

Fig. 6

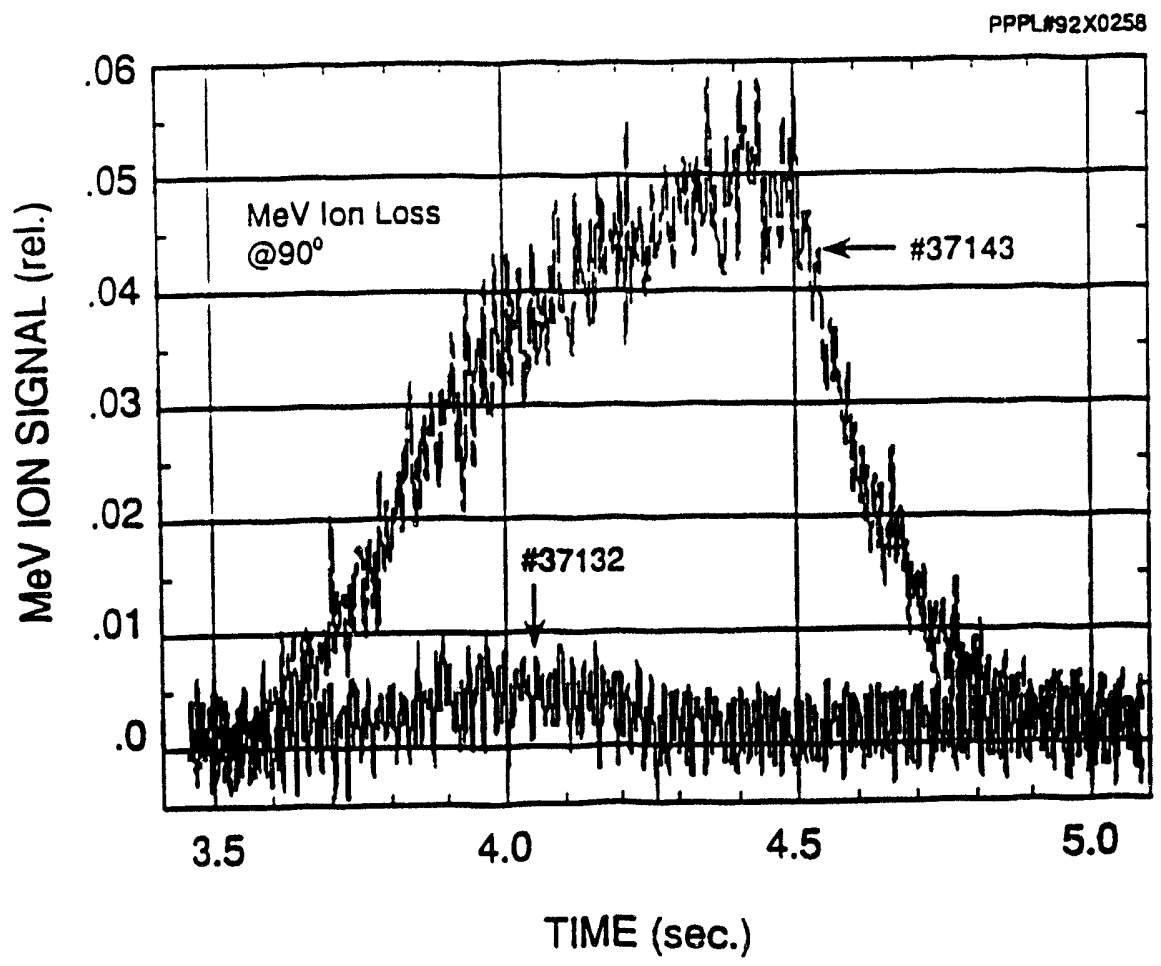

Fig. 7 


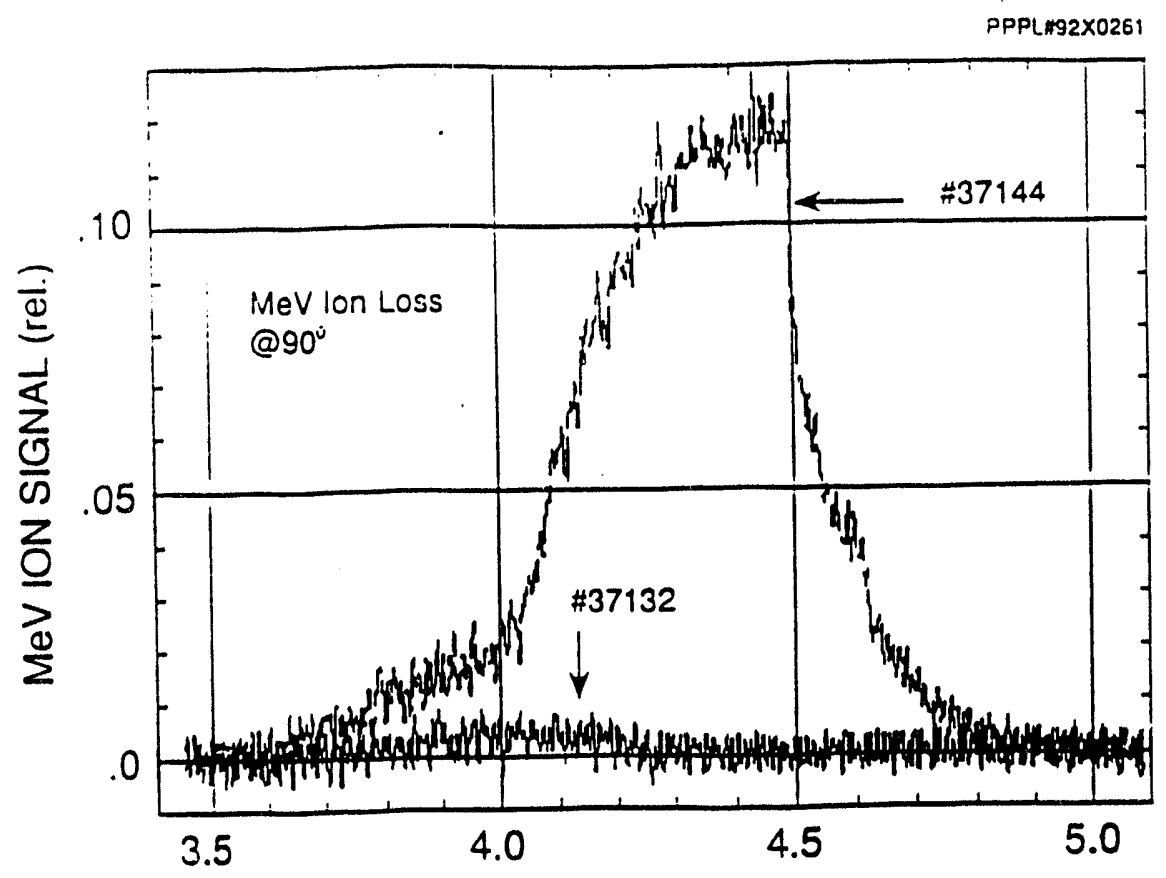

TIME (sec.)

Fig. 8 (a)

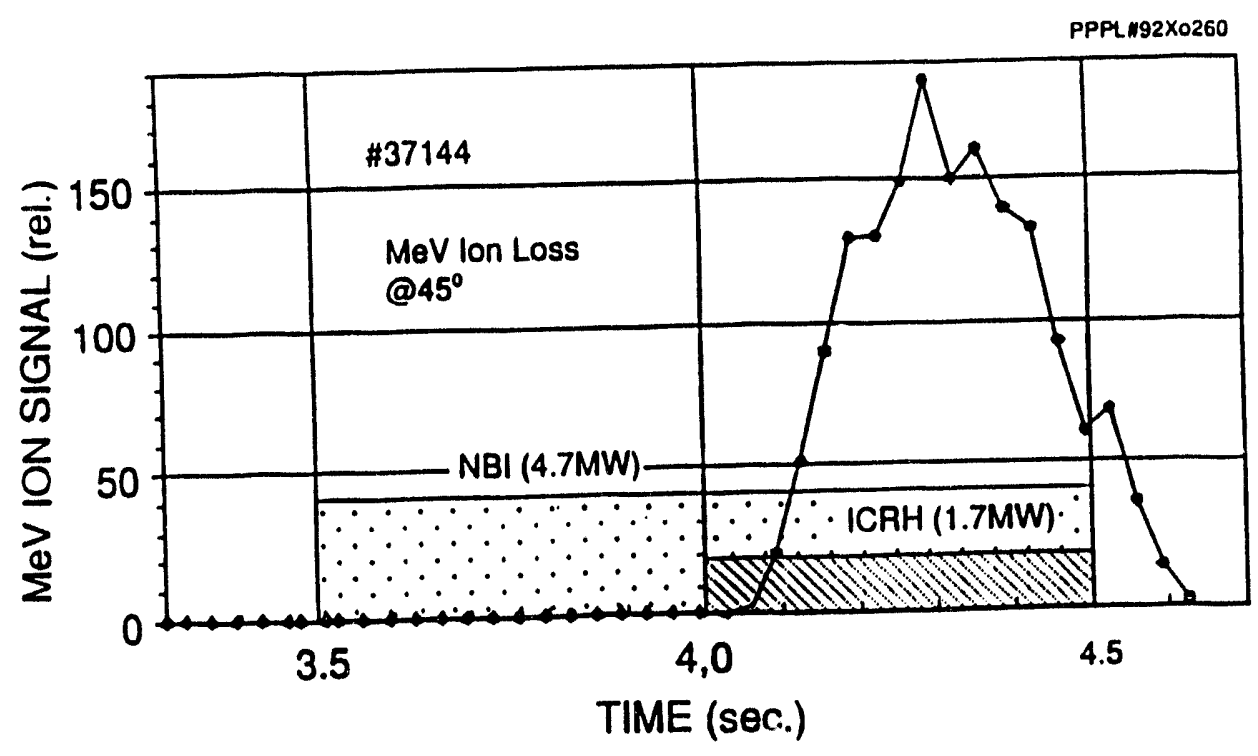

Fig. 8 (b) 
'PPPL\#92X0262

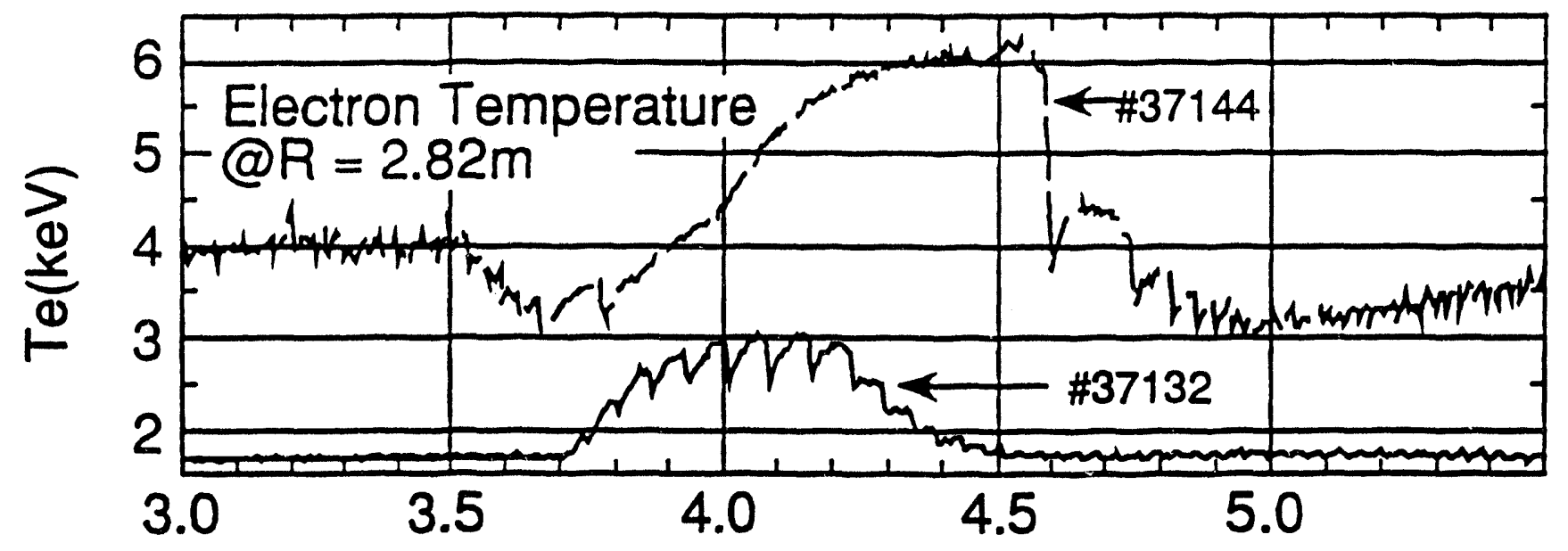

$\times 10^{15}$

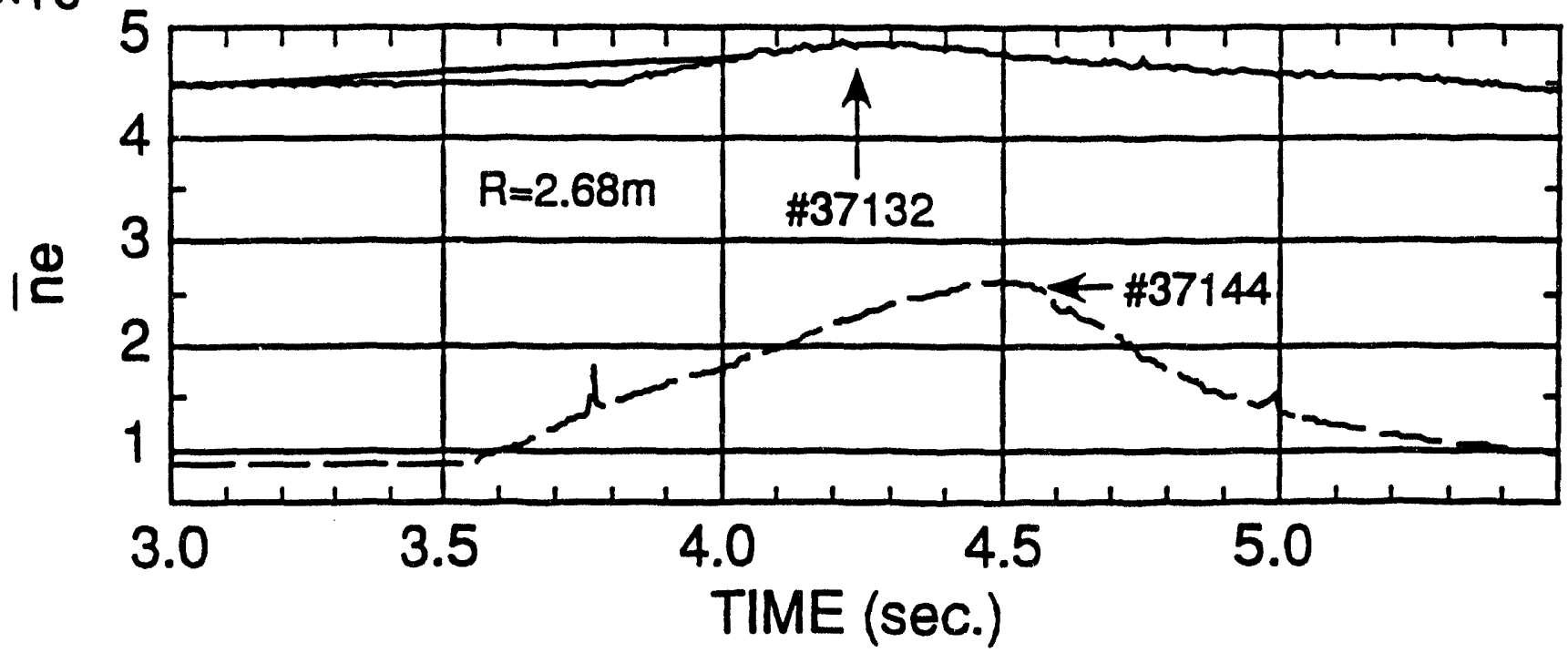

Fig. 9 

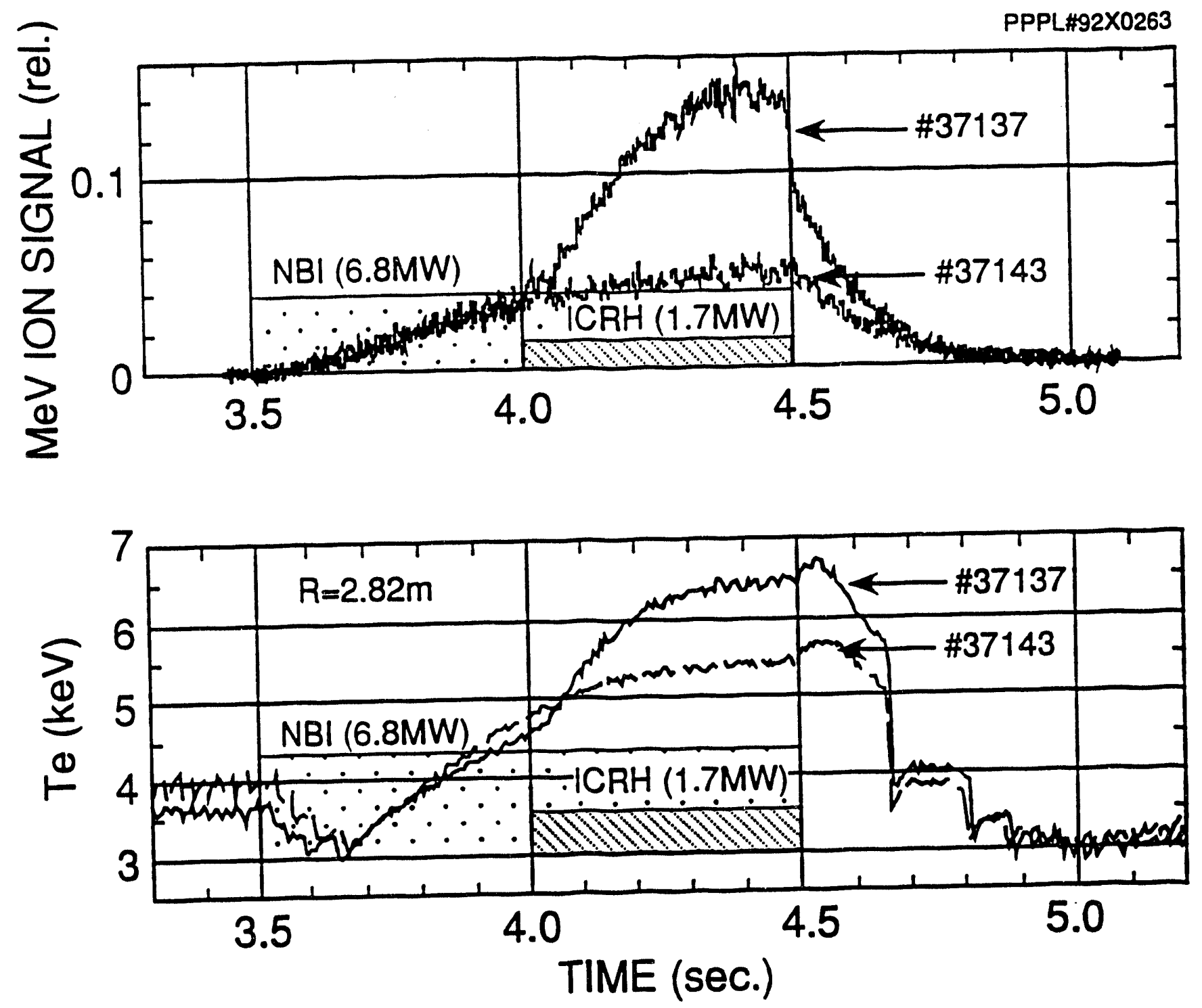

Fig. 10 


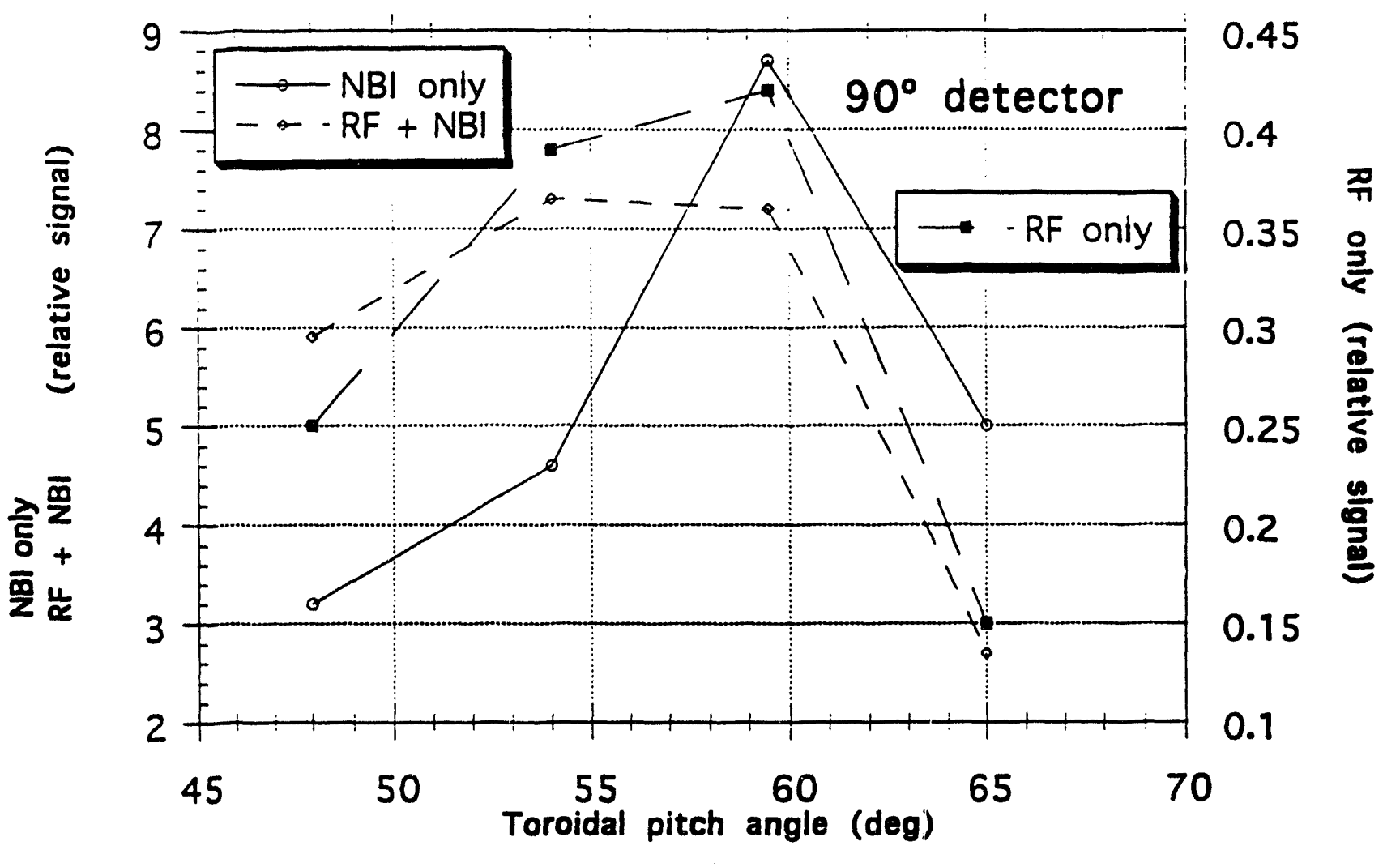

Fig. 11 


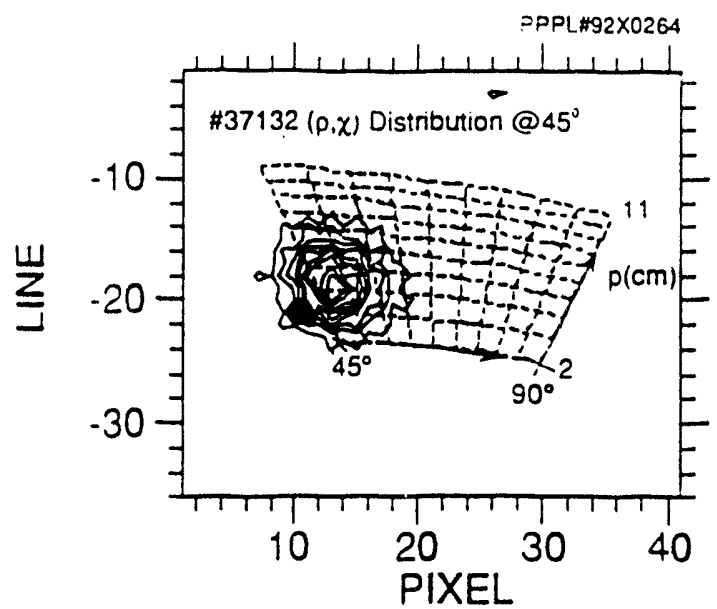

Fig. 12 (a)

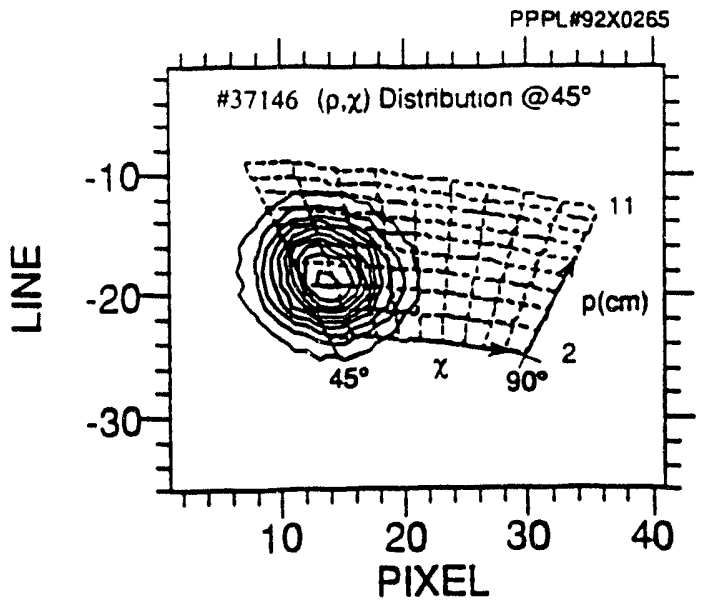

Fig. 12 (b) 


\section{Poloidal View}

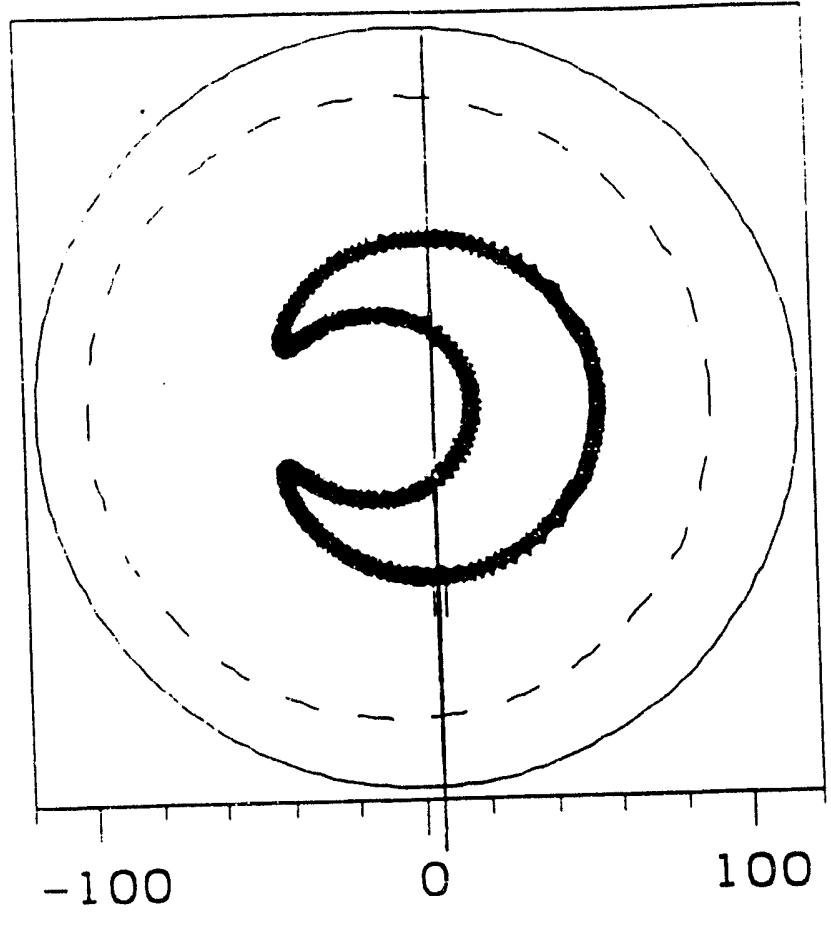

Fig. 13 (a)

\section{Poloidal View}

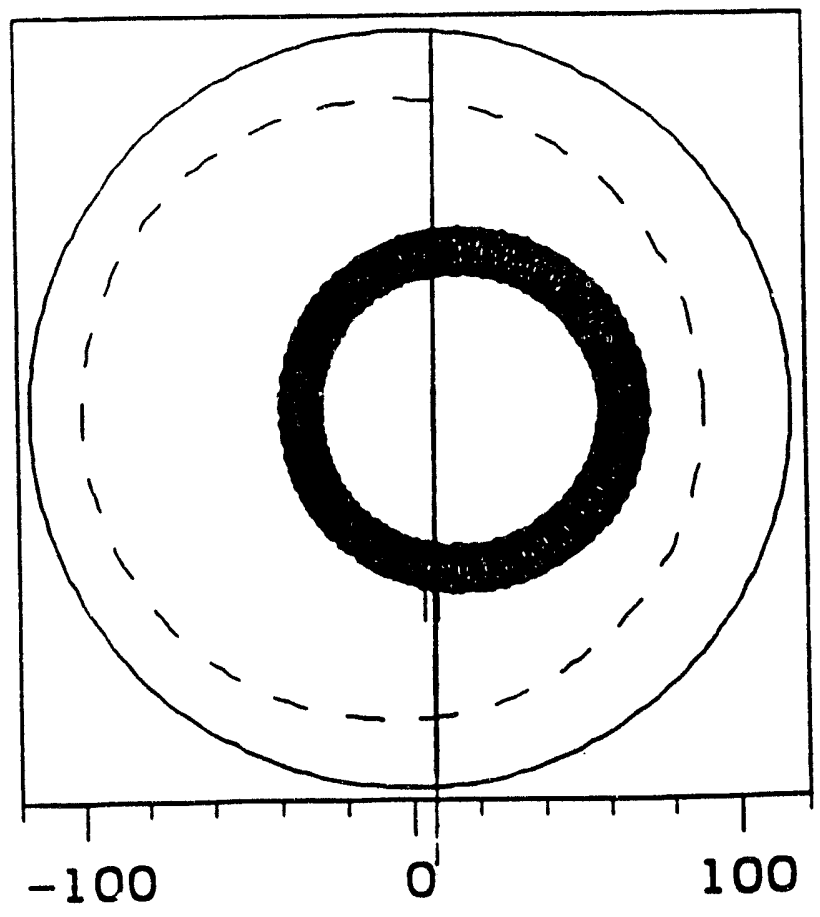

Fig. 13 (b) 
loss region at $(R=27(), z=-1(1)$

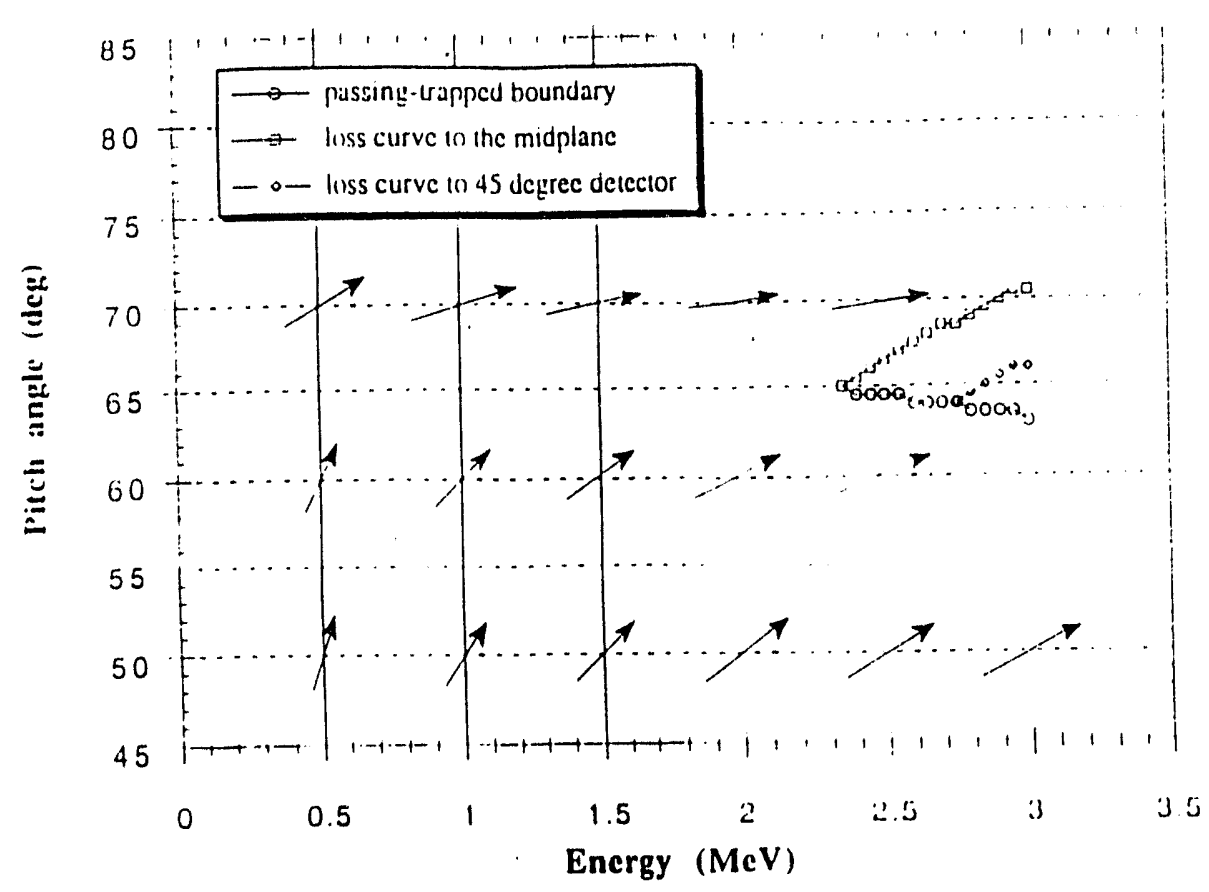

Fig. 14 (a)

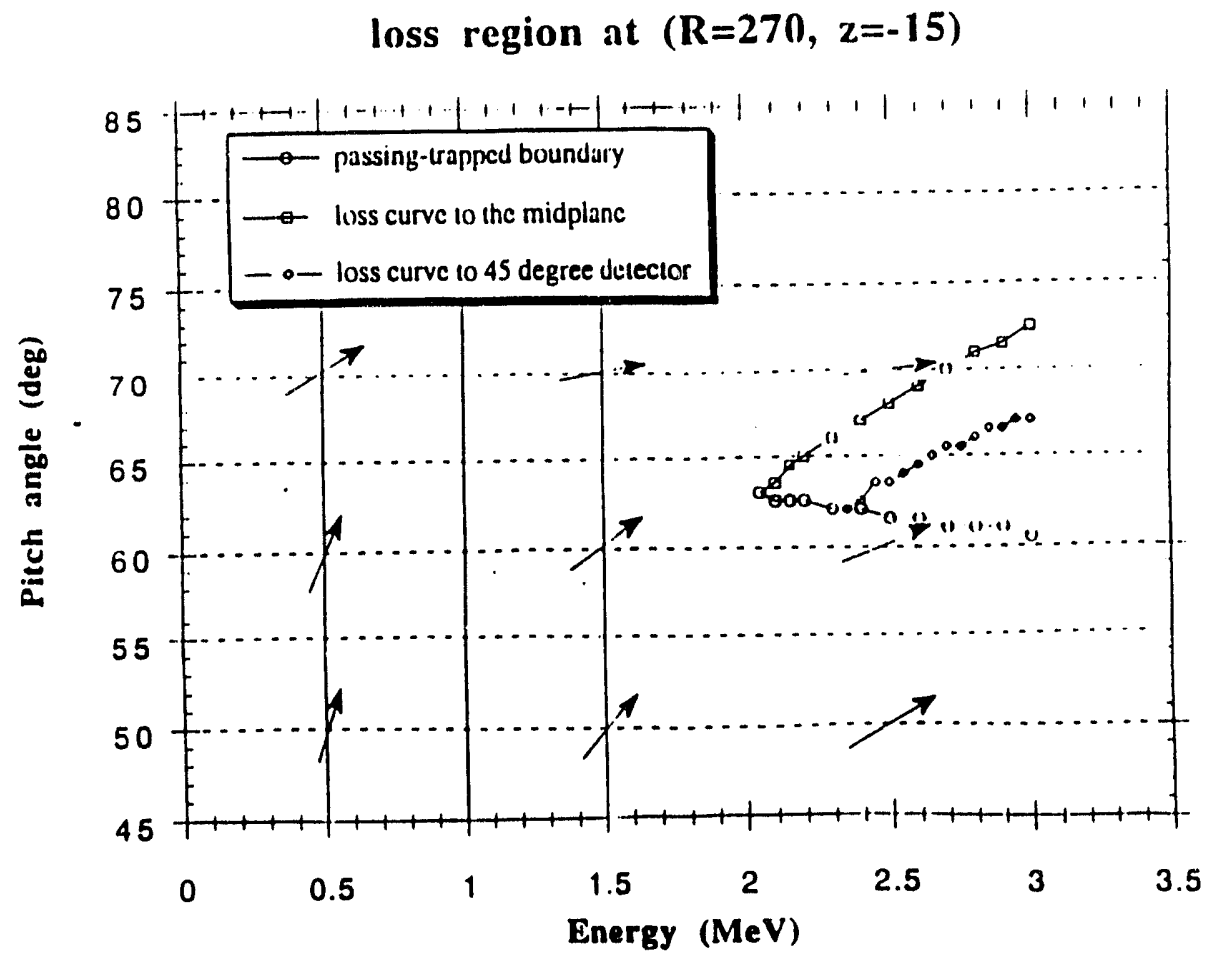

Fig. 14 (b) 
Ioss region at $(R=27(), z=-20)$

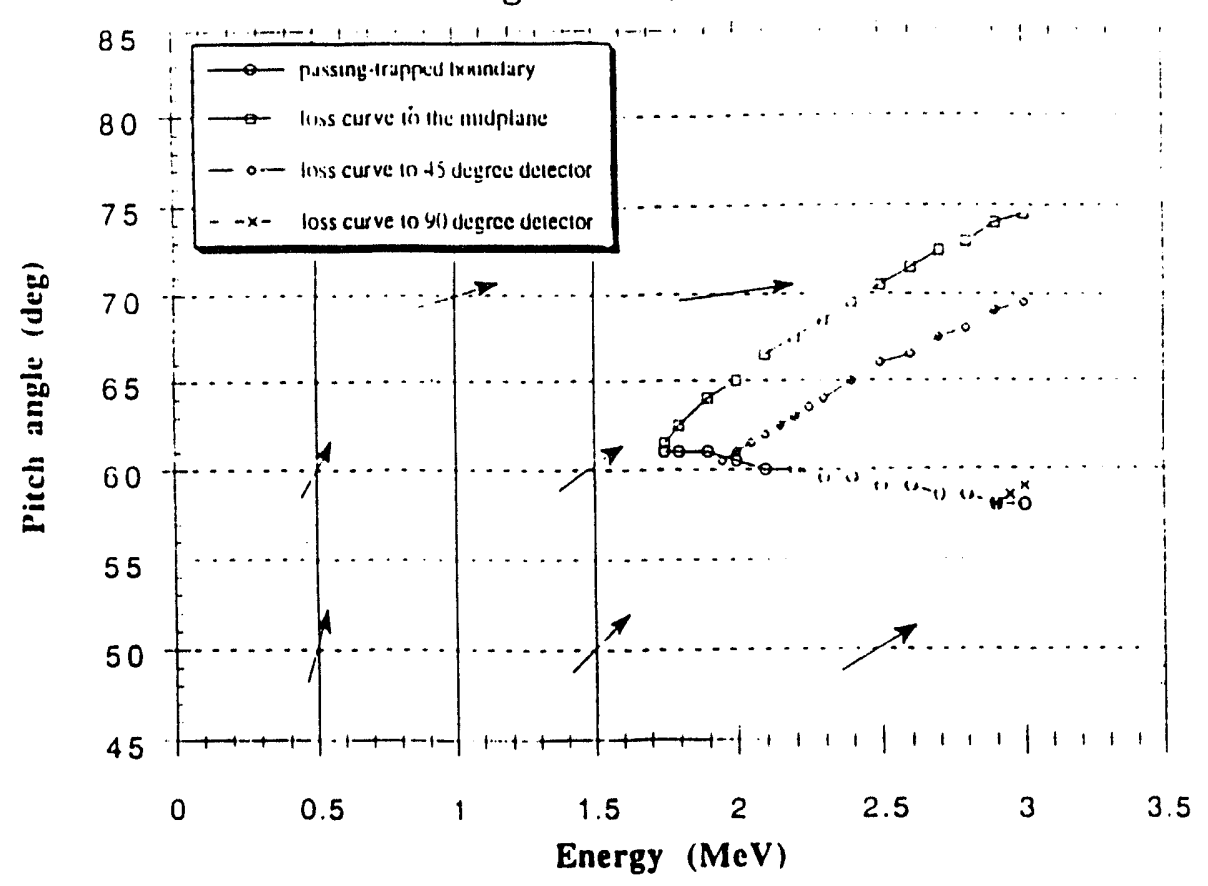

Fig. 14 (c)

loss region at $(R=270, z=-25)$

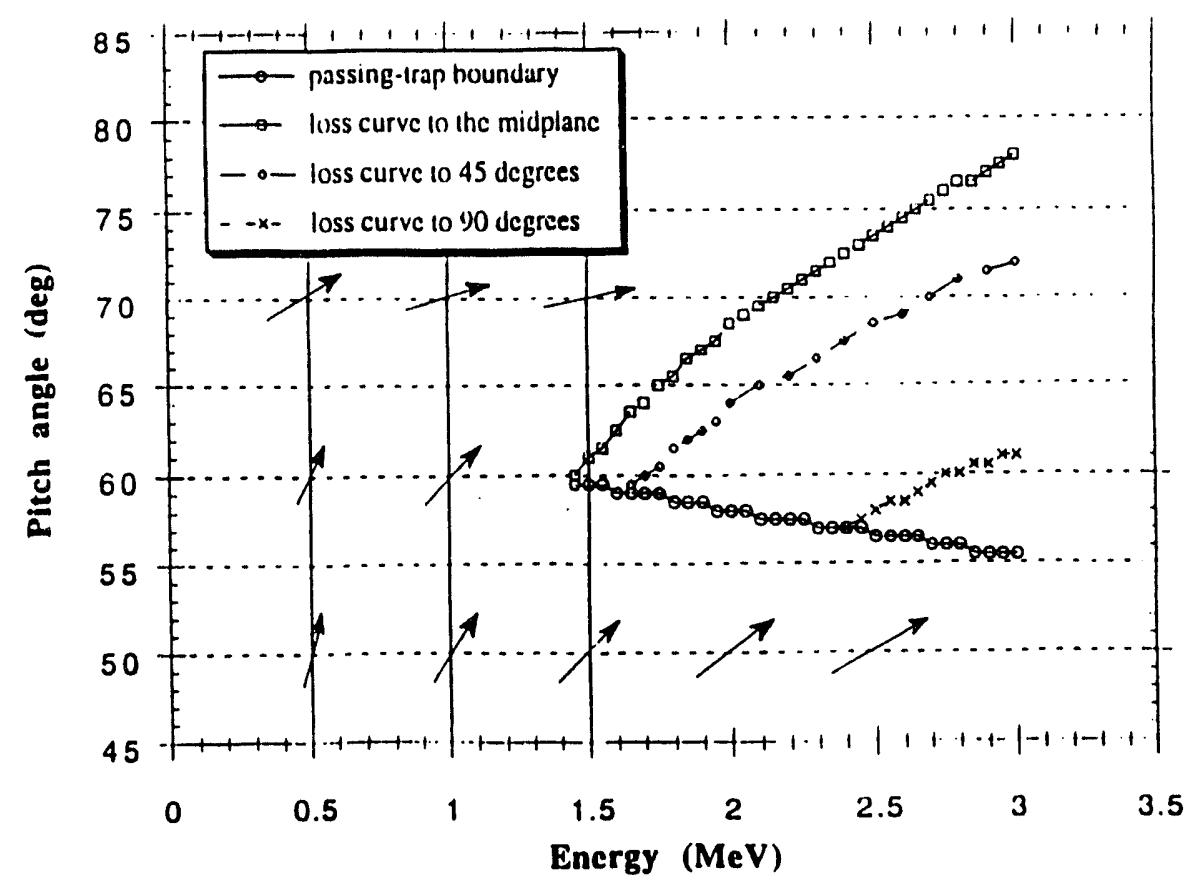

Fig. 14 (d) 
loss region at $(R=270, z=-35)$

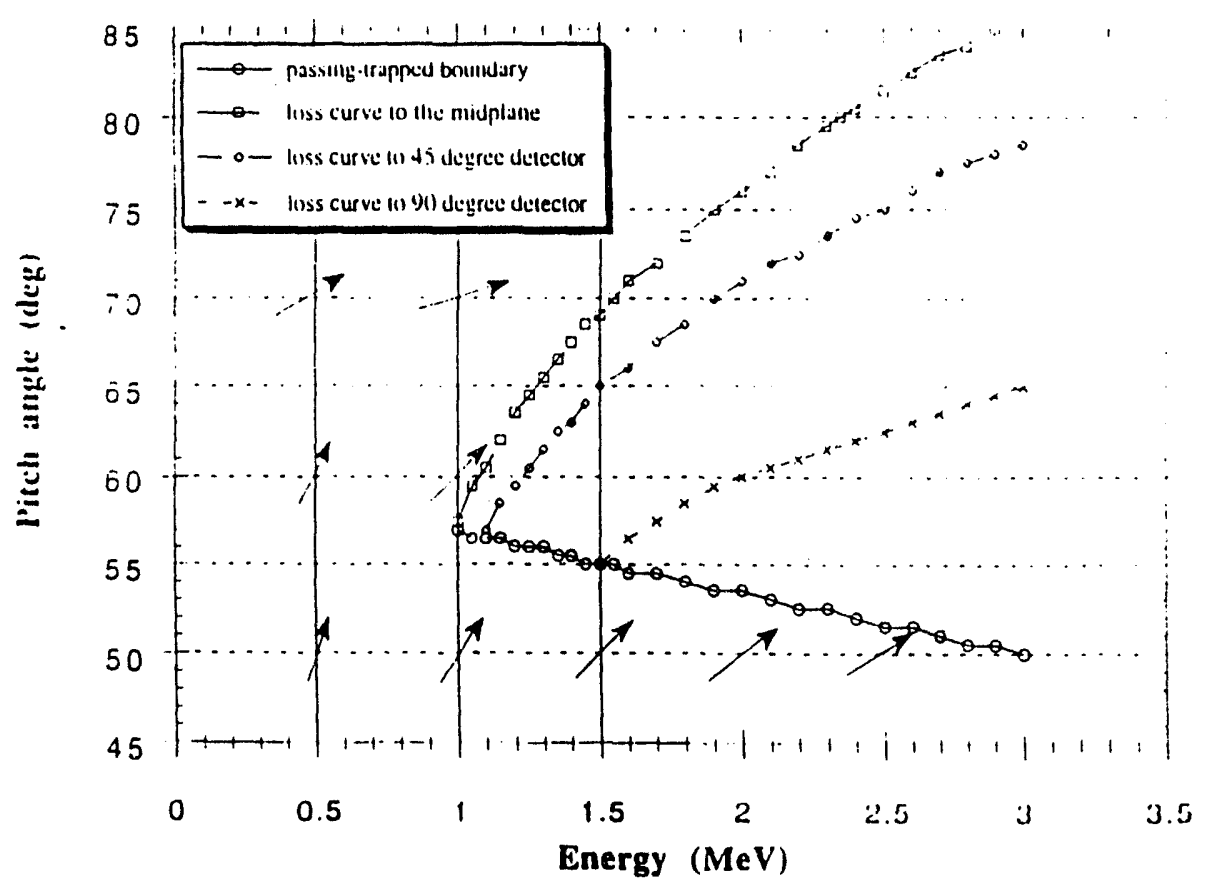

Fig. 14 (e) 


\section{EXTERNAL DISTRIBUTION IN ADDITION TO UC-420}

Dr. F. Paoloni, Univ. of Wollongong, AUSTRALIA

Prof. M.H. Brennan, Univ. of Sydney, AUSTRALIA

Plasma Research Lab., Australian Nat. Univ., AUSTRALIA

Prof. I.R. Jones, Flinders Univ, AUSTRALIA

Prof. F. Cap, Inst. for Theoretical Physics, AUSTRIA

Prof. M. Heindler, Institut für Theoretische Physik, AUSTRIA

Prol. M. Goossens, Astronomisch Instituut, BELGIUM

Ecole Royale Militaire, Lab. de Phy. Plasmas, BELGIUM

Commission-European, DG. XII-Fusion Prog., BELGIUM

Prot. R. Bouciqué, Rijksuniversiteit Gent, BELGIUM

Dr. P.H. Sakanaka, Instituto Fisica, BRAZIL

Prof. Dr. I.C. Nascimento, Instituto Fisica, Sao Paulo, BRAZIL Instituto Nacional Do Pesquisas Espaciais-INPE, BRAZIL Documents Otfice, Atomic Energy of Canada Ltd., CANADA Ms. M. Morin, CCFMTokamak de Varennes, CANADA

Dr. M.P. Bachynski, MPB Technologies, Inc., CANADA

Dr. H.M. Skarsgard, Univ. of Saskatchewan, CANADA

Prof. J. Teichmann, Univ. of Montreal, CANADA

Prof. S.R. Sreenivasan, Univ. of Calgary, CANADA

Prof. T.W. Johnston, INRS-Energie, CANADA

Dr. R. Bolton, Centre canadien de fusion magnétique, CANADA

Dr. C.R. James., Univ. of Alberta, CANADA

Dr. P. Lukác, Komenského Universzita, CZECHO-SLOVAKIA

The Librarian, Culham Laboratory, ENGLAND

Library, R61, Rutherford Appleton Laboratory, ENGLAND

Mrs. S.A. Hutchinson, JET Library, ENGLAND

Dr. S.C. Sharma, Univ. of South Pacific, FIJI ISLANDS

P. Mähönen, Univ. of Helsinki, FINLAND

Prof. M.N. Bussac, Ecole Polytechnique, FRANCE

C. Mouttet, Lab. de Physique des Milieux lonisés, FRANCE

J. Radet, CEN/CADARACHE - Bat 506, FRANCE

Prof. E. Economou, Univ. of Crete, GREECE

Ms. C. Rinni, Univ. of loannina, GREECE

Preprint Library, Hungarian Academy of Sci., HUNGARY

Dr. B. DasGupta, Saha Inst. of Nuclear Physics, INDIA

Dr. P. Kaw, Inst. for Plasma Research, INDIA

Dr. P. Rosenau, Israel Inst. of Technology, ISRAEL

Librarian, Intemational Center for Theo Physics, ITALY

Miss C. De Palo, Associazione EURATOM-ENEA , ITALY

Dr. G. Grosso, Istituto di Fisica del Plasma, ITALY

Prof. G. Rostangni, Istituto Gas lonizzati Del Cnr, ITALY
Dr. H. Yamato, Toshiba Res \& Devel Center, JAPAN

Prof. I. Kawakami, Hiroshima Univ., JAPAN

Prof. K. Nishikawa, Hiroshima Univ., JAPAN

Librarian, Naka Fusion Research Establishment, JAERI, JAPAN

Director, Japan Atomic Energy Research Inst., JAPAN

Prol. S. Itoh, Kyushu Univ., JAPAN

Research Info. Ctr., National Instit. for Fusion Science, JAPAN

Prof. S. Tanaka, Kyoto Univ., JAPAN

Library, Kyoto Univ., JAPAN

Prof. N. Inoue, Univ. of Tokyo, JAPAN

Secretary, Plasma Section, Electrotechnical Lab., JAPAN

S. Mori, Technical Advisor, JAERI, JAPAN

Dr. O. Mitarai, Kumamoto Inst. of Technology, JAPAN

Dr. G.S. Lee, Korea Basic Sci. Ctr., KOREA

J. Hyeon-Sook, Korea Atomic Energy Research Inst., KOREA

D.I. Choi, The Korea Adv. Inst. of Sci. \& Tech., KOREA

Prof. B.S. Liley, Univ. of Waikato, NEW ZEALAND Inst of Physics, Chinese Acad Sci PEOPLE'S REP. OF CHINA Library, Inst. of Plasma Physics, PEOPLE'S REP. OF CHINA Tsinghua Univ. Library, PEOPLE'S REPUBLIC OF CHINA Z. Li, S.W. Inst Physics, PEOPLE'S REPUBLIC OF CHINA Prof. J.A.C. Cabral, Instituto Superior Tecnico, PORTUGAL Prof. M.A. Hellberg, Univ. of Natal, S. AFRICA Prof. D.E. Kim, Pohang Inst. of Sci. \& Tech., SO. KOREA Prof. C.I.E.M.A.T, Fusion Division Library, SPAIN Dr. L. Stenflo, Univ. of UMEA, SWEDEN Library, Royal Inst. of Technology, SWEDEN Prof. H. Wilhelmson, Chalmers Univ. of Tech., SWEDEN Centre Phys. Des Plasmas, Ecole Polytech, SWITZERLAND Bibliotheek, Inst. Voor Plasma-Fysica, THE NETHERLANDS Asst. Prof. Dr. S. Cakir, Middle East Tech. Univ., TURKEY Dr. V.A. Glukhikh,Sci. Res. Inst. Electrophys.I Apparatus, USSR Dr. D.D. Ryutov, Siberian Branch of Academy of Sci., USSR Dr. G.A. Eliseev, I.V. Kurchatov Inst., USSR Librarian, The Ukr.SSR Academy of Sciences, USSR Dr. L.M. Kovrizhnykh, Inst. of General Physics, USSR Kemforschungsanlage GmbH, Zentralbibliothek, W. GERMANY Bibliothek, Inst. Für Plasmaforschung, W. GERMANY Prof. K. Schindler, Ruhr-Universitát Bochum, W. GERMANY Dr. F. Wagner, (ASDEX), Max-Planck-Institut, W. GERMANY Librarian, Max-Planck-Institut, W. GERMANY 

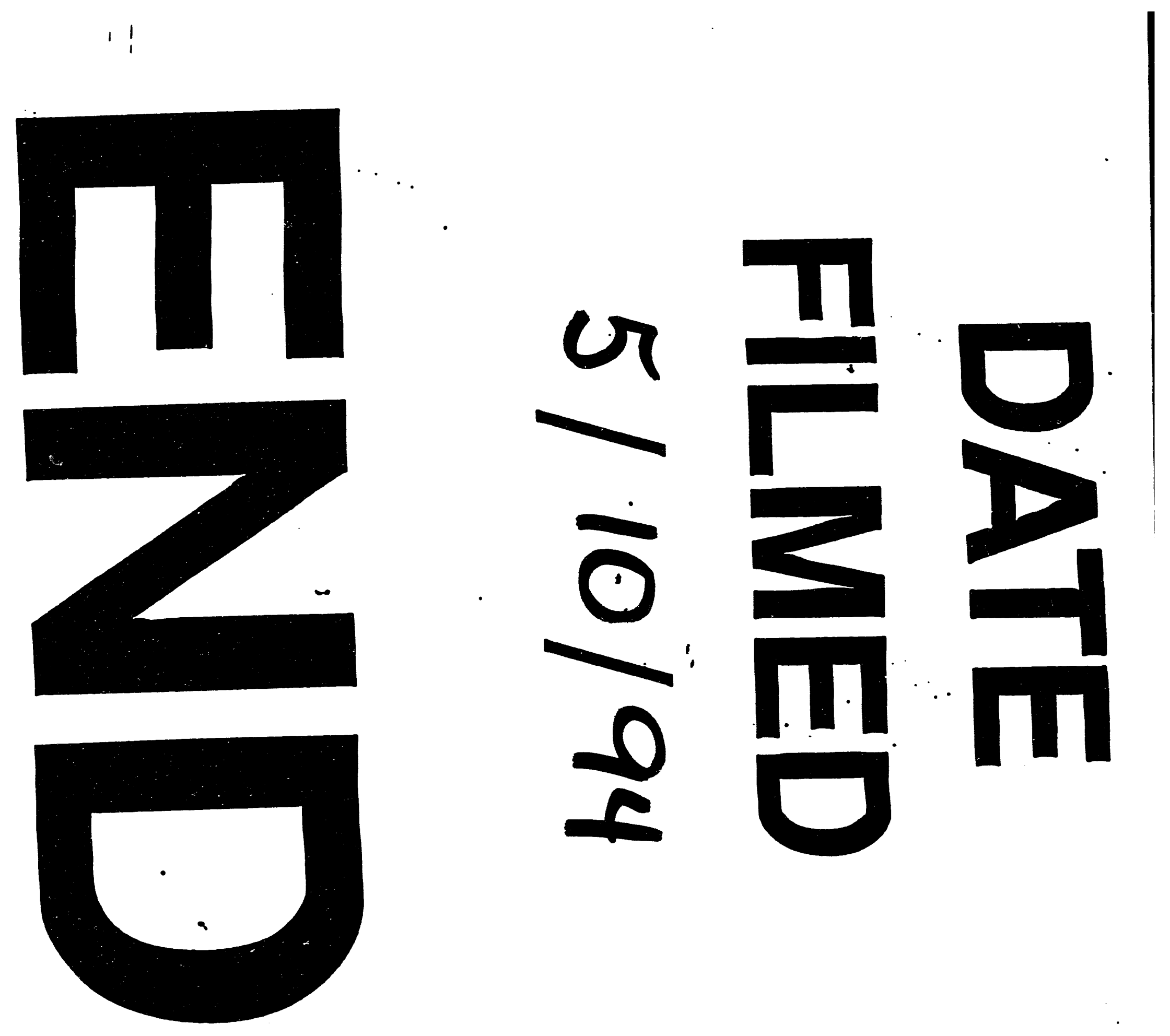
